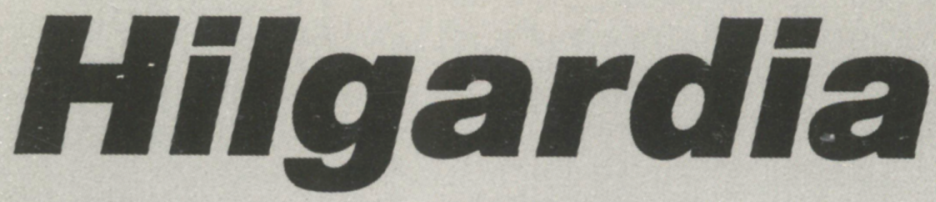

A. JOURNAL OF AGRICULTURAL SCIENCE PUBLISHED BY THE CALIFORNIA AGRICULTURAL EXPERIMENT STATION

Volume 58 - Number 4 - November 1990

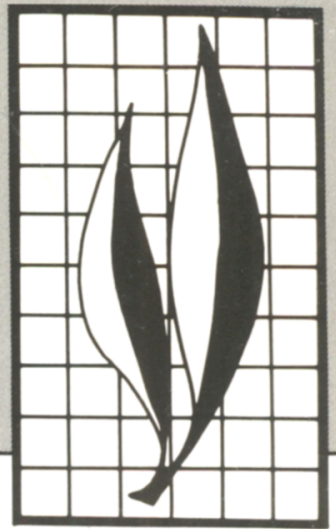

\title{
Dynamic Modelling of a Cross-Flow Rice Dryer
}

David Platt, Tom R. Rumsey, and Ahmet Palazoglu 


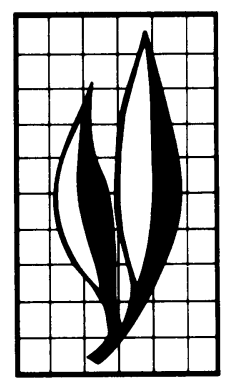

\begin{abstract}
A general dynamic model of a cross-flow dryer is developed from fundamental balance equations. Six dimensionless groups that govern the process are defined, and the resulting dimensionless equations are solved with the Method of Lines, using the Advanced Continuous Simulation Language (ACSL) software package. The mesh influence on the numerical solution is investigated. Stiffness analysis is performed for the system of partial differential equations, and the assumption of quasi-steady state for the air is discussed. Application of the model to rice-drying experiments shows good agreement. The results underline the potential of the model and the numerical solution strategy needed for critical physical insight into the operation of cross-flow rice dryers.
\end{abstract}

\title{
THE AUTHORS:
}

David Platt is on leave from RAFAEL, Israel.

Tom R. Rumsey, Department of Agricultural Engineering, University of California, Davis.

Ahmet Palazoglu, Department of Chemical Engineering, University of California, Davis. 


\section{Dynamic Modelling of a Cross-Flow Rice Dryer ${ }^{1}$}

David Platt, Tom R. Rumsey, and Abmet Palazoglu

\section{$\stackrel{1}{1}$ INTRODUCTION}

STEADY-STATE MODEls of continuous cross-flow grain dryers have existed for more than 20 years. Thompson et al. (1968) used mass and energy balances to model both fixed-bed and continuous-flow grain dryers. Bakker-Arkema et al. (1974) presented a two-dimensional, steady-state partial differential equation (PDE) model for cross-flow dryers. Variations of this model have been used to analyze cross-flow drying (Otten et al. 1980; Chandra et al. 1981; Fontana et al. 1982; Bakker-Arkema et al. 1983).

Simplified, transient models of continuous cross-flow dryers have been developed in conjunction with the design and analysis of control systems to regulate exit grain moisture content. Zachariah and Isaacs (1966) used a simplified model to design a control system that manipulated grain flow in order to regulate grain moisture. Holtman and Zachariah (1969) used a similar model to design optimal controls that manipulated grain flow based on two performance indices: (1) the integral of the square of the difference between the exit and set point moisture and (2) no underdrying along with the same integral of the squared error. Marchant (1985) presented a simplified dryer model that was used to investigate several control schemes for regulating grain moisture. Whitfield (1986) adapted a steady-state dryer model to simulate the transient, closed-loop behavior of control systems for concurrent- and counter-flow dryers.

More detailed models based on PDEs have only recently been derived for the transient analysis of continuous-flow grain dryers. Schisler et al. (1982) presented a transient, concurrent-flow dryer model for use in moisture-control system design. Laws and Parry (1983) derived a general model, consisting of a set of PDEs that can be used for the dynamic analysis of convective grain dryers. From their general model, models for the four basic types of dryers can be deduced: fixed-bed, cross-flow, concurrent-flow, and counter-flow. Eltigani and Bakker-Arkema (1987) also presented a transient PDE model to simulate a cross-flow corn dryer. Gui et al. (1988) reviewed various graindrying simulation methods.

In this paper, we developed a general mathematical model for a cross-flow rice dryer based on earlier studies by Rumsey $(1986,1988)$. Starting with fundamental material and energy balance equations, we describe the dynamic behavior of this process. Design options such as an inverter and air recirculation are also considered. Our primary goal is to establish a mathematical setting in which dryer behavior can be accurately perceived and explained. Section 2 introduces the modeling equations and dimensionless parameters that govern the process. A numerical solution procedure is presented in section 3, and model extensions are discussed in section 4 where the model is tested against field data.

\footnotetext{
'Accepted for publication January 31, 1990.
} 


\section{2 \\ MODEL DEVELOPMENT}

This section presents the general PDEs describing the transient drying process in a cross-flow dryer. A derivation of similar PDEs is given by Rumsey (1986). His equation for the grain temperature assumes a quasi-steady state for the air humidity. In the following equations, we include the accumulation terms corresponding to the air, and present a general analysis.

\section{Basic Equations}

A cross-section of the dryer is shown in figure 1. Symbols are defined in the nomenclature section (page 44).

Material balance on the water in the grain:

$$
-\mathrm{G}_{\mathrm{p}} \frac{\partial \mathrm{M}}{\partial \mathrm{y}}-\rho(1-\epsilon) \mathrm{R}=\rho(1-\epsilon) \frac{\partial \mathrm{M}}{\partial \mathrm{t}} .
$$

Material balance on the water vapor in the air:

$$
-\mathrm{G}_{\mathrm{a}} \frac{\partial \mathrm{W}}{\partial \mathrm{x}}+\rho(1-\epsilon) \mathrm{R}=\rho_{\mathrm{a}} \epsilon \frac{\partial \mathrm{W}}{\partial \mathrm{t}} .
$$

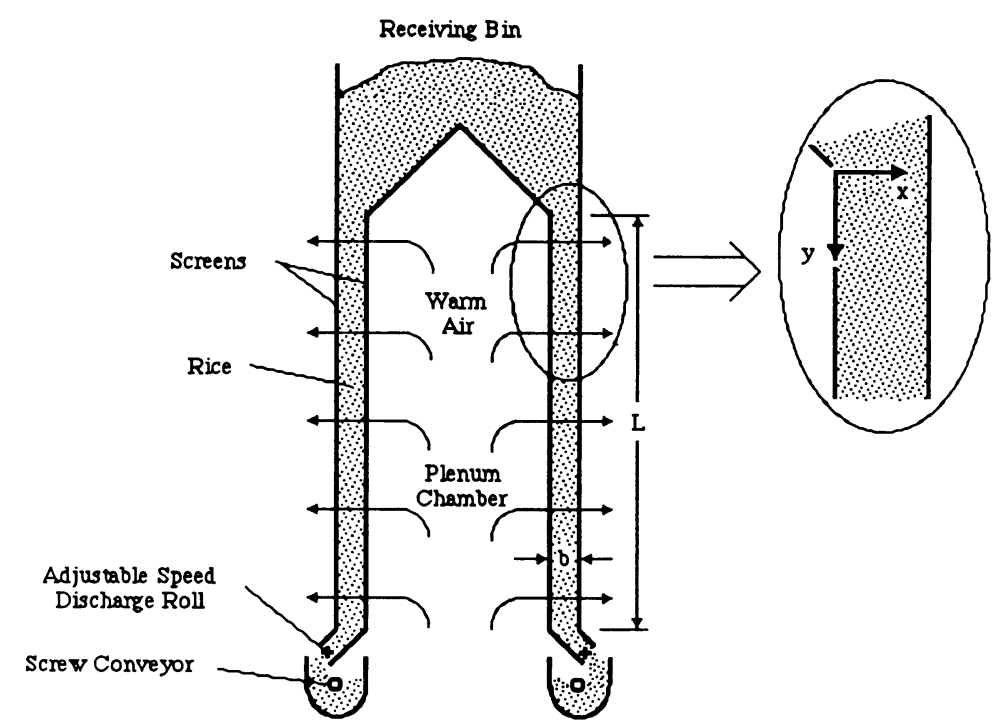

Fig. 1. Schematic of cross-flow rice dryer. 
Energy balance on the grain (expressing $\partial M / \partial t$ by Eq. [1]):

$$
-\mathrm{G}_{\mathrm{p}} \mathrm{C}_{\mathrm{pg}} \frac{\partial \theta}{\partial \mathrm{y}}+\mathrm{h}(\mathrm{T}-\theta)-\rho(1-\epsilon) \mathrm{R}\left(\mathrm{H}_{\mathrm{w}}-\mathrm{h}_{\mathrm{w}}\right)=\rho(1-\epsilon) \mathrm{C}_{\mathrm{pg}} \frac{\partial \theta}{\partial \mathrm{t}} .
$$

Energy balance on the air phase (expressing $\partial \mathrm{W} / \partial \mathrm{t}$ by Eq. [2]):

$$
-\mathrm{G}_{\mathrm{a}} \mathrm{C}_{\mathrm{pa}} \frac{\partial \mathrm{T}}{\partial \mathrm{x}}-\mathrm{h}(\mathrm{T}-\theta)=\rho_{\mathrm{a}} \epsilon \mathrm{C}_{\mathrm{pa}} \frac{\partial \mathrm{T}}{\partial \mathrm{t}} \text {. }
$$

$\mathrm{C}_{\mathrm{pg}}$ and $\mathrm{C}_{\mathrm{pa}}$ in Equations [3] and [4] represent the specific heats of the wet grain and the humid air, respectively, based on a dry mass unit. $\mathrm{C}_{\mathrm{pg}}$ and $\mathrm{C}_{\mathrm{pa}}$ are assumed to be constant over the range in which $\mathrm{M}, \mathrm{W}, \mathrm{T}$, and $\theta$ prevail in the dryer. The primary difference between this model and the one presented by Eltigani and Bakker-Arkema (1987) is in Equation [1]. Their water balance on the grain neglects the effect of the rate of drying (second term on the left-hand side of Equation [1], which can erroneously lead to the conclusion of no drying $(\partial M / \partial y=0)$ at steady-state. Note that ' $\partial M / \partial t$ ' term does not represent the actual rate of drying unless a fixed-bed dryer is used. When the grain flow is set to zero, our equations (as well as those by Laws and Parry, 1983) reduce to the fixed-bed model, whereas those given by Eltigani and Bakker-Arkema indicate that no drying would occur.

This system of PDEs is subject to the following general boundary conditions

$$
\begin{aligned}
& \mathrm{W}(0, \mathrm{y}, \mathrm{t})=\mathrm{W}_{\text {in }}(\mathrm{y}, \mathrm{t}), \\
& \mathrm{T}(0, \mathrm{y}, \mathrm{t})=\mathrm{T}_{\text {in }}(\mathrm{y}, \mathrm{t}), \\
& \mathrm{M}(\mathrm{x}, 0, \mathrm{t})=\mathrm{M}_{\text {in }}(\mathrm{x}, \mathrm{t}), \text { and } \\
& \theta(\mathrm{x}, 0, \mathrm{t})=\theta_{\text {in }}(\mathrm{x}, \mathrm{t}) .
\end{aligned}
$$

If we assume that the feed to the dryer is not a function of position, the boundary conditions become

$$
\begin{aligned}
& \mathrm{W}(0, \mathrm{y}, \mathrm{t})=\mathrm{W}_{\text {in }}(\mathrm{t}), \\
& \mathrm{T}(0, \mathrm{y}, \mathrm{t})=\mathrm{T}_{\text {in }}(\mathrm{t}), \\
& \mathrm{M}(\mathrm{x}, 0, \mathrm{t})=\mathrm{M}_{\text {in }}(\mathrm{t}), \text { and } \\
& \theta(\mathrm{x}, 0, \mathrm{t})=\theta_{\text {in }}(\mathrm{t}) .
\end{aligned}
$$

The system of PDEs is subject to the initial conditions

$$
\begin{aligned}
& \mathrm{M}(\mathrm{x}, \mathrm{y}, 0)=\mathrm{M}_{\mathrm{o}}(\mathrm{x}, \mathrm{y}), \\
& \theta(\mathrm{x}, \mathrm{y}, 0)=\theta_{\mathrm{o}}(\mathrm{x}, \mathrm{y}), \\
& \mathrm{W}(\mathrm{x}, \mathrm{y}, 0)=\mathrm{W}_{\mathrm{o}}(\mathrm{x}, \mathrm{y}), \text { and } \\
& \mathrm{T}(\mathrm{x}, \mathrm{y}, 0)=\mathrm{T}_{\mathrm{o}}(\mathrm{x}, \mathrm{y}) .
\end{aligned}
$$

The solution of the set [1] to [4] with the boundary conditions [5a] to [5d] and the initial conditions [7a] to [7d] requires empirical expressions for the rate of drying, $R$, and the convective heat transfer coefficient, $h$.

As our examples relate to the drying of rough rice, empirical expressions for $\mathrm{R}$ and $\mathrm{h}$, corresponding to rough rice, will be given. 


\section{Empirical Expressions for $\mathbf{R}$ and $\mathrm{h}$ in Rice Drying}

\section{Empirical relations for rate of drying}

$\mathrm{R}$ is a function of $\mathrm{M}, \theta, \mathrm{W}$, and $\mathrm{T}$. The thin-layer equation developed by Wang and Singh (1978)

$$
\mathrm{R}=10^{-5}[4.6889+0.10558(\mathrm{~T}+\theta)-4.3667 \mathrm{rh}](\mathrm{M}-\mathrm{Me})
$$

is used for this model, where the equilibrium moisture content $M_{e}$ is given by Chung's equation (ASAE 1988):

$$
\mathrm{M}_{\mathrm{e}}=\mathrm{E}-\mathrm{F} \cdot \ln [-(\mathrm{T}+\mathrm{G}) \cdot \ln (\mathrm{rh})]
$$

For rough rice, the coefficients are given as

$$
\begin{aligned}
& E=0.29394, \\
& F=0.046015, \text { and } \\
& G=35.703 .
\end{aligned}
$$

The relative humidity of the air, rh, which appears in Equations [8] and [9], is given according to its definition (assuming the air is an ideal gas and the pressure is atmospheric) by

$$
\mathrm{rh}=1.01325 \cdot 10^{5} \cdot \mathrm{WM}_{\mathrm{a}} /\left(\mathrm{WM}_{\mathrm{a}}+\mathrm{M}_{\mathrm{w}}\right) \mathrm{P}_{\mathrm{v}},
$$

where $P_{v}$ is the vapor pressure of water at temperature $T$ and is found by Wagner's equation (Reid et al. 1987)

$$
\ln \left(\mathrm{P}_{\mathrm{v}} / \mathrm{P}_{\mathrm{c}}\right)=(1-\mathrm{z})^{-1}\left[\mathrm{Az}+\mathrm{Bz}^{1.5}+\mathrm{Cz}^{3}+\mathrm{Dz}^{6}\right],
$$

where $z=1-(T+273.15) /\left(T_{c}+273.15\right)$, and the coefficients for water are

$$
\begin{aligned}
& \mathrm{A}=-7.76451, \\
& \mathrm{~B}=1.45838, \\
& \mathrm{C}=-2.77580 \\
& \mathrm{D}=-1.23303, \\
& \mathrm{~T}_{\mathrm{c}}=374.15, \text { and } \\
& \mathrm{P}_{\mathrm{c}}=2.212 \cdot 10^{7} .
\end{aligned}
$$

\section{Empirical relation for $h$}

The correlation for volumetric convective heat transfer coefficient in a packed bed of rice (Wang, Rumsey, and Singh 1979) is

$$
\mathrm{h}=8.69 \cdot 10^{4} \cdot \mathrm{G}_{\mathrm{a}}{ }^{1.3} \text {. }
$$

This correlation is found to be good for $T$ and $G_{a}$ in the range $50<T<60$ and $0.25<\mathrm{G}_{\mathrm{a}}<0.5$, which is typical for rice dryers. Lacking another correlation, we assume that Equation [12] is also good for a moving bed, for which $G_{p}$ is small in comparison to $\mathrm{G}_{\mathbf{a}}$. 


\section{Dimensionless Groups}

Defining dimensionless variables and writing the PDEs [1] to [4] in terms of these variables, results in a new system of equations, which is governed by only six dimensionless groups. The advantages of the dimensionless representation are its compactness and generality, which result in a better understanding of both the physical process and the mathematical nature of the PDEs describing the process.

By using the dimensionless representation, the drying operation is characterized by six dimensionless parameters, rather than by 15 dimensional ones. This representation does not depend on the unit system chosen. Furthermore, each dimensionless system of PDEs corresponds to a family of dryers, all having the same six dimensionless groups, rather than to a specific dryer. Moreover, the operational analysis of a dryer and the comparison between operations of different dryers are better established by examining the corresponding six dimensionless groups using the similarity principle. Mathematically, the normalized form of the variables in the dimensionless representation also allows good understanding of the stiff nature of the system of PDEs.

\section{Dimensionless variables}

Define the following averages:

$$
\begin{aligned}
& \overline{\mathrm{W}}_{\mathrm{in}}(0)=\frac{\int_{0}^{\mathrm{L}} \mathrm{W}_{\mathrm{in}}(\mathrm{u}, 0) \mathrm{du}}{\mathrm{L}}, \\
& \overline{\mathrm{T}}_{\mathrm{in}}(0)=\frac{\int_{0}^{\mathrm{L}} \mathrm{T}_{\mathrm{in}}(\mathrm{u}, 0) \mathrm{du}}{\mathrm{L}}, \\
& \overline{\mathrm{M}}_{\mathrm{in}}(0)=\frac{\int_{0}^{\mathrm{b}} \mathrm{M}_{\mathrm{in}}(\mathrm{u}, 0) \mathrm{du}}{\mathrm{b}}, \\
& \bar{\theta}_{\mathrm{in}}(0)=\frac{\int_{0}^{\mathrm{b}} \theta_{\text {in }}(\mathrm{u}, 0) \mathrm{du}}{\mathrm{b}} .
\end{aligned}
$$

These lead to the dimensionless dependent variables

$$
\mathrm{M}^{*}=\mathrm{M} / \overline{\mathrm{M}}_{\mathrm{in}}(0)
$$




$$
\begin{aligned}
& \theta^{*}=\frac{\theta-\bar{\theta}(0)}{\overline{\mathrm{T}}_{\mathrm{in}}(0)-\bar{\theta}_{\mathrm{in}}(0)}, \\
& \mathrm{W}^{*}=\mathrm{W} / \overline{\mathrm{W}}_{\mathrm{in}}(0), \text { and } \\
& \mathrm{T}^{*}=\frac{\mathrm{T}-\bar{\theta}_{\mathrm{in}}(0)}{\overline{\mathrm{T}}_{\mathrm{in}}(0)-\bar{\theta}_{\mathrm{in}}(0)}
\end{aligned}
$$

From Equations [13a] and [14b], the average values of $M^{*}, \theta^{*}, \mathrm{~W}^{*}$, and $\mathrm{T}^{*}$ in the air and grain inlets at $\mathrm{t}=0$ are $1,0,1$, and 1 , respectively.

With no drastic changes in the inlets, the definitions [14a] to [14d] assure that the maximum values for $\mathrm{M}^{*}, \theta^{*}, \mathrm{~W}^{*}$, and $\mathrm{T}^{*}$ in the dryer are of the order of magnitude of 1. While $\mathrm{M}^{*}$ and $\mathrm{W}^{*}$ are inherently positive, $\theta^{*}$ and $\mathrm{T}^{*}$ may be negative due to the endothermic nature of the drying process.

Denote by $t_{r}$ the residence time of the grain corresponding to its initial flow rate

$$
\mathrm{t}_{\mathrm{r}}=\mathrm{L} \rho(1-\epsilon) / \mathrm{G}_{\mathrm{p}}(0)
$$

and define the dimensionless forms of the independent variables

$$
\begin{aligned}
& \mathrm{x}^{*}=\mathrm{x} / \mathrm{b}, \\
& \mathrm{y}^{*}=\mathrm{y} / \mathrm{L}, \text { and } \\
& \mathrm{t}^{*}=\mathrm{t} / \mathrm{t}_{\mathrm{r}} .
\end{aligned}
$$

From Equation [16], $x^{*}$ and $y^{*}$ range between 0 and 1, while one unit of the dimensionless time $t^{*}$ is equivalent to the initial residence time of the grain.

Define dimensionless forms for those parameters in Equations [1] to [4], which may change with time: $\mathrm{G}_{\mathrm{a}}, \mathrm{G}_{\mathrm{p}}$, h, and $\mathrm{R}$. The other parameters, $\rho, \epsilon, \rho_{\mathrm{a}}, \mathrm{C}_{\mathrm{pg}}, \mathrm{C}_{\mathrm{pa}}$, and $\left(H_{w}-h_{w}\right)$, are assumed to be constant in time and space.

Assume that the flow rates $G_{a}$ and $G_{p}$ depend on time only:

$$
\begin{aligned}
& \mathrm{G}_{\mathrm{a}}=\mathrm{G}_{\mathrm{a}}(\mathrm{t}) \text {, and } \\
& \mathrm{G}_{\mathrm{p}}=\mathrm{G}_{\mathrm{p}}(\mathrm{t}) .
\end{aligned}
$$

From $[12]$ and $[17 \mathrm{a}]$,

$$
\mathrm{h}=\mathrm{h}(\mathrm{t}) \text {. }
$$

Denote by $R_{c}$ the drying rate, based on the average conditions at the dryer inlets at $\mathrm{t}=0$ :

$$
\mathrm{R}_{\mathrm{c}}=\mathrm{R}\left(\overline{\mathrm{M}}_{\mathrm{in}}(0), \bar{\theta}_{\mathrm{in}}(0), \overline{\mathrm{W}}_{\mathrm{in}}(0), \overline{\mathrm{T}}_{\mathrm{in}}(0)\right) .
$$

$R_{c}$ will be referred to as "the characteristic drying rate."

The dimensionless forms of $G_{a}, G_{p}, h$, and $R$ will be defined as

$$
\begin{aligned}
& \mathrm{G}_{\mathrm{a}}^{*}=\mathrm{G}_{\mathrm{a}} / \mathrm{G}_{\mathrm{a}}(0), \\
& \mathrm{G}_{\mathrm{p}}{ }^{*}=\mathrm{G}_{\mathrm{p}} / \mathrm{G}_{\mathrm{p}}(0), \\
& \mathrm{h}^{*}=\mathrm{h} / \mathrm{h}(0), \text { and } \\
& \mathrm{R}^{*}=\mathrm{R} / \mathrm{R}_{\mathrm{c}} .
\end{aligned}
$$


Based on the above definitions and assumptions, the system of Equations [1] to [4] in dimensionless form becomes

$$
\begin{aligned}
& \frac{\partial \mathrm{M}^{*}}{\partial \mathrm{t}^{*}}=-\mathrm{G}_{\mathrm{p}}^{*} \frac{\partial \mathrm{M}^{*}}{\partial \mathrm{y}^{*}}-\alpha \mathrm{R}^{*}, \\
& \frac{\partial \mathrm{W}^{*}}{\partial \mathrm{t}^{*}}=\beta\left[-\mathrm{G}_{\mathrm{a}}^{*} \frac{\partial \mathrm{W}^{*}}{\partial \mathrm{x}^{*}}+\gamma \mathrm{R}^{*}\right], \\
& \frac{\partial \theta^{*}}{\partial \mathrm{t}^{*}}=-\mathrm{G}_{\mathrm{p}}^{*} \frac{\partial \theta^{*}}{\partial \mathrm{y}^{*}}+\delta \mathrm{h}^{*}\left(\mathrm{~T}^{*}-\theta^{*}\right)-\alpha \phi \mathrm{R}^{*}, \text { and } \\
& \frac{\partial \mathrm{T}^{*}}{\partial \mathrm{t}^{*}}=\beta\left[-\mathrm{G}_{\mathrm{a}}^{*} \frac{\partial \mathrm{T}^{*}}{\partial \mathrm{x}^{*}}-\psi \mathrm{h}^{*}\left(\mathrm{~T}^{*}-\theta^{*}\right)\right],
\end{aligned}
$$

where $\alpha, \beta, \gamma, \delta, \phi$, and $\psi$ are dimensionless groups defined by

$$
\begin{aligned}
& \alpha=\frac{\rho(1-\epsilon) \mathrm{L} \mathrm{R}_{\mathrm{c}}}{\mathrm{G}_{\mathrm{p}}(0) \overline{\mathrm{M}}_{\mathrm{in}}(0)}, \\
& \beta=\frac{\mathrm{G}_{\mathrm{a}}(0) \rho(1-\epsilon) \mathrm{L}}{\mathrm{G}_{\mathrm{p}}(0) \rho_{\mathrm{a}} \epsilon \mathrm{b}}, \\
& \gamma=\frac{\rho(1-\epsilon) \mathrm{b} \mathrm{\textrm {R } _ { \mathrm { c } }}}{\mathrm{G}_{\mathrm{a}}(0) \overline{\mathrm{W}}_{\mathrm{in}}(0)} \\
& \delta=\frac{\mathrm{h}(0) \mathrm{L}}{\mathrm{G}_{\mathrm{p}}(0) \mathrm{C}_{\mathrm{pg}}}, \\
& \phi=\frac{\overline{\mathrm{M}}_{\mathrm{in}}(0)\left(\mathrm{H}_{\mathrm{w}}-\mathrm{h}_{\mathrm{w}}\right)}{\mathrm{C}_{\mathrm{pg}}\left(\overline{\mathrm{T}}_{\mathrm{in}}(0)-\bar{\theta}_{\mathrm{in}}(0)\right)} \\
& \psi=\frac{\mathrm{h}(0) \mathrm{b}}{\mathrm{G}_{\mathrm{a}}(0) \mathrm{C}_{\mathrm{pa}}} .
\end{aligned}
$$

If the flow rates $G_{a}$ and $G_{p}$ are time-invariant (which means a time-invariant $h$ as well), then

$$
\begin{aligned}
& \mathrm{G}_{\mathrm{a}}^{*}=1, \\
& \mathrm{G}_{\mathrm{p}}{ }^{*}=1, \text { and } \\
& \mathrm{h}^{*}=1 .
\end{aligned}
$$

In this case, the set of Equations [21] to [24] yields a more compact form.

To complete the formulation of the model in its dimensionless form, we have to express the boundary and the initial conditions in terms of dimensionless variables as well.

Define the dimensionless forms of $\mathrm{W}_{\mathrm{in}}, \mathrm{T}_{\mathrm{in}}, \mathrm{M}_{\mathrm{in}}$, and $\theta_{\mathrm{in}}$ in a manner analogous to the definitions of $\mathrm{W}^{*}, \mathrm{~T}^{*}, \mathrm{M}^{*}$, and $\theta^{*}$, respectively:

$$
\mathrm{W}_{\text {in }}^{*}=\mathrm{W}_{\text {in }} / \mathrm{W}_{\text {in }}(0),
$$




$$
\begin{aligned}
& \mathrm{T}_{\mathrm{in}}^{*}=\frac{\mathrm{T}_{\mathrm{in}}-\bar{\theta}_{\mathrm{in}}(0)}{\overline{\mathrm{T}}_{\mathrm{in}}(0)-\bar{\theta}_{\mathrm{in}}(0)}, \\
& \mathrm{M}_{\mathrm{in}}^{*}=\mathrm{M}_{\mathrm{in}} / \overline{\mathrm{M}}_{\mathrm{in}}(0), \text { and } \\
& \theta_{\mathrm{in}}^{*}=\frac{\theta_{\mathrm{in}}-\bar{\theta}_{\mathrm{in}}(0)}{\overline{\mathrm{T}}_{\mathrm{in}}(0)-\bar{\theta}_{\mathrm{in}}(0)}
\end{aligned}
$$

Define the dimensionless forms of the initial distributions in the dryer, $\mathbf{M}_{\mathrm{o}}, \theta_{\mathrm{o}}, \mathrm{W}_{\mathrm{o}}$, and $\mathrm{T}_{\mathrm{o}}$ :

$$
\begin{aligned}
& \mathrm{M}_{\mathrm{o}}^{*}=\mathrm{M}_{\mathrm{o}} / \overline{\mathrm{M}}_{\mathrm{in}}(0), \\
& \theta_{\mathrm{o}}^{*}=\frac{\theta_{\mathrm{o}}-\bar{\theta}_{\mathrm{in}}(0)}{\overline{\mathrm{T}}_{\mathrm{in}}(0)-\bar{\theta}_{\mathrm{in}}(0)}, \\
& \mathrm{W}_{\mathrm{o}}^{*}=\mathrm{W}_{\mathrm{o}} / \overline{\mathrm{W}}_{\mathrm{in}}(0), \text { and } \\
& \mathrm{T}_{\mathrm{o}}^{*}=\frac{\mathrm{T}_{\mathrm{o}}-\bar{\theta}_{\mathrm{in}}(0)}{\overline{\mathrm{T}}_{\mathrm{in}}(0)-\bar{\theta}_{\mathrm{in}}(0)} .
\end{aligned}
$$

The boundary conditions [5a] to [5d] in their dimensionless form are

$$
\begin{aligned}
& \mathrm{W}^{*}\left(0, \mathrm{y}^{*}, \mathrm{t}^{*}\right)=\mathrm{W}_{\mathrm{in}}{ }^{*}\left(\mathrm{y}^{*}, \mathrm{t}^{*}\right), \\
& \mathrm{T}^{*}\left(0, \mathrm{y}^{*}, \mathrm{t}^{*}\right)=\mathrm{T}_{\mathrm{in}}{ }^{*}\left(\mathrm{y}^{*}, \mathrm{t}^{*}\right), \\
& \mathrm{M}^{*}\left(\mathrm{x}^{*}, 0, \mathrm{t}^{*}\right)=\mathrm{M}_{\mathrm{in}}{ }^{*}\left(\mathrm{x}^{*}, \mathrm{t}^{*}\right), \text { and } \\
& \theta^{*}\left(\mathrm{x}^{*}, 0, \mathrm{t}^{*}\right)=\theta_{\mathrm{in}}{ }^{*}\left(\mathrm{x}^{*}, \mathrm{t}^{*}\right) .
\end{aligned}
$$

The initial conditions [7a] to [7d] in their dimensionless form are

$$
\begin{aligned}
& \mathrm{M}^{*}\left(\mathrm{x}^{*}, \mathrm{y}^{*}, 0\right)=\mathrm{M}_{\mathrm{o}}^{*}\left(\mathrm{x}^{*}, \mathrm{y}^{*}\right), \\
& \theta^{*}\left(\mathrm{x}^{*}, \mathrm{y}^{*}, 0\right)=\theta_{\mathrm{o}}^{*}\left(\mathrm{x}^{*}, \mathrm{y}^{*}\right), \\
& \mathrm{W}^{*}\left(\mathrm{x}^{*}, \mathrm{y}^{*}, 0\right)=\mathrm{W}_{\mathrm{o}}^{*}\left(\mathrm{x}^{*}, \mathrm{y}^{*}\right), \text { and } \\
& \mathrm{T}^{*}\left(\mathrm{x}^{*}, \mathrm{y}^{*}, 0\right)=\mathrm{T}_{\mathrm{o}}^{*}\left(\mathrm{x}^{*}, \mathrm{y}^{*}\right) .
\end{aligned}
$$

The set of PDEs [21] to [24] (including the definitions of the dimensionless groups $\alpha, \beta, \gamma, \delta, \phi$, and $\psi$ and the correlations for $\mathrm{R}^{*}$ and $\left.\mathrm{h}^{*}\right)$, subject to the boundary conditions [29a] to [29d] and to the initial conditions [30a] to [30d], constitutes a complete, dimensionless model for the rice-drying process in a cross-flow dryer.

\section{The significance of dimensionless groups}

The solution to the dimensionless model depends not only on the six dimensionless groups $\alpha, \beta, \gamma, \delta, \phi$, and $\psi$, but on the dimensionless parameters $\mathrm{R}^{*}, \mathrm{G}_{\mathrm{p}}{ }^{*}, \mathrm{G}_{\mathrm{a}}{ }^{*}$, and $\mathrm{h}^{*}$ as well, which means dependence on $\overline{\mathrm{M}}_{\mathrm{in}}(0), \bar{\theta}_{\mathrm{in}}(0), \overline{\mathrm{W}}_{\mathrm{in}}(0), \overline{\mathrm{T}}_{\mathrm{in}}(0), \overline{\mathrm{G}}_{\mathrm{p}}(\mathrm{t})$, and $\overline{\mathrm{G}}_{\mathrm{a}}(\mathrm{t})$. However, if there are no large variations in the inlet conditions and in the flow 
rates, all of the above dimensionless parameters, which appear in the right-hand side. of Equations [21] to [24], will be generally of the order of magnitude of one. In a steady operation, $G_{p}{ }^{*}, G_{a}^{*}$, and $h^{*}$ are exactly $1 . R^{*}$ varies in time and space, but when normalized in relation to a characteristic rate, assume that it ranges around one, as in the numerical example of the next section shows. As $G_{p}{ }^{*}, G_{a}{ }^{*}, h^{*}$, and $R^{*}$ are of the same range of values for all dryers, the drying process depends chiefly on the values of the six dimensionless groups $\alpha, \beta, \gamma, \delta, \phi$, and $\psi$. All but $\beta$ influence both the dynamic and the steady-state behaviors, whereas $\beta$ influences only the dynamic behavior.

It can be shown by integrating Equation [21] twice relative to $x^{*}$ and to $y^{*}$ between 0 and 1 , that for constant inlet conditions and grain flow, the dimensionless average moisture at the outlet at steady-state is given by

$$
\overline{\mathrm{M}}_{\text {out }}{ }^{*}(\mathrm{~s} . \mathrm{s})=1-\alpha \overline{\mathrm{R}}_{\text {s.s }}^{*},
$$

where $\mathrm{R}^{*}$ is the average dimensionless rate of drying at the steady-state, given by

$$
\overline{\mathrm{R}}_{\text {s.s }}=\int_{0}^{1} \int_{0}^{1} \mathrm{R}_{\text {s.s }} \mathrm{dx} \mathrm{dy}^{*} \text {. }
$$

$\overline{\mathrm{R}}^{*}{ }_{\text {s.s }}$ is a function of the process inlet conditions and the six dimensionless groups. It is of an order of magnitude of 1 (most probably less than 1 , because $R_{c}$ is based on inlet conditions), so 1- $\alpha$ can serve as a lower bound for the dimensionless average outlet moisture at steady-state. The higher the value of $\alpha$, the better the drying process expected.

One may recognize that, by definition of [25a], $\alpha$ represents the ratio between the rate of drying and the flow rate of water carried by the grain into the dryer. A typical value for $\alpha$ is 0.1 .

A similar integration of Equation [22] leads to the equation

$$
\overline{\mathrm{W}}_{\text {out }}{ }^{*}(\mathrm{~s} . \mathrm{s})=1+\gamma \overline{\mathrm{R}}_{\text {s.s. }}^{*} \text {. }
$$

$1+\gamma$ may serve as an upper bound for the dimensionless average outlet humidity at steady-state. As the value of $\gamma$ increases, so does the humidity. Looking at the definition of $\gamma(25 \mathrm{c})$, this conclusion is clear, because $\gamma$ is the ratio between the rate of drying and the flow rate of water carried by the air into the dryer. A typical value for $\gamma$ is 1 .

Substituting $\overline{\mathrm{R}}^{*}{ }_{\text {s.s }}$ from Equation [31] into [33] gives the water mass balance on the dryer, which relates the outlet humidity to the outlet moisture:

$$
\overline{\mathrm{W}}_{\text {out }}{ }^{*}(\mathrm{~s} . \mathrm{s})=1+\frac{\gamma\left(1-\overline{\mathrm{M}}_{\mathrm{out}}^{*}[\mathrm{~s} . \mathrm{s}]\right)}{\alpha} \text {. }
$$

$\overline{\mathrm{R}}_{\text {s.s }}^{*}$, the average drying rate at steady-state, can be evaluated from experimental results either by Equation [31] or [33].

The same procedure on Equations [23] and [34] leads to the relations

$$
\begin{aligned}
& \bar{\theta}_{\text {out }}{ }^{*}(\mathrm{~s} . \mathrm{s})=\delta \overline{\mathrm{T}^{*}-\theta^{*}}-\alpha \phi \overline{\mathrm{R}}^{*}{ }_{\text {s.s }} \text {, and } \\
& 1-\overline{\mathrm{T}}_{\text {out }}{ }^{*}(\mathrm{~s} . \mathrm{s})=\psi \overline{\mathrm{T}^{*}-\theta^{*}}
\end{aligned}
$$

where 


$$
\overline{\mathrm{T}^{*}-\theta^{*}}=\int_{0}^{1} \int_{0}^{1}\left(\mathrm{~T}^{*}{ }_{\mathrm{s} . \mathrm{s}}-\theta^{*}{ }_{\mathrm{s} . \mathrm{s}}\right) \mathrm{dx} \mathrm{dy}^{*} .
$$

Substituting $\overline{\mathrm{T}^{*}-\theta^{*}}$ from Equation [35] into Equation [36] gives the overall energy balance on the dryer:

$$
\bar{\theta}_{\text {out }}{ }^{*}(\mathrm{~s} . \mathrm{s})=\frac{\delta}{\psi}\left(1-\overline{\mathrm{T}}_{\text {out }}{ }^{*}(\mathrm{~s} . \mathrm{s})\right)-\alpha \phi \overline{\mathrm{R}}_{\text {s.s }} .
$$

Substituting $\overline{\mathrm{R}}_{\text {s.s }}^{*}$ in Equation [31] yields

$$
\bar{\theta}_{\text {out }} *(\text { s.s })=\frac{\delta}{\psi}\left(1-\overline{\mathrm{T}}_{\text {out }}^{*}(\mathrm{~s} . \mathrm{s})\right)-\phi\left(1-\overline{\mathrm{M}}_{\mathrm{out}}{ }^{*}(\mathrm{~s} . \mathrm{s})\right) \text {. }
$$

The average temperature difference in the dryer at steady-state can be evaluated from experimental results either by Equation [35] or [36]. Thus, Equations [34] and [39] give us two relations between the four steady-state outlets of the dryer in terms of $\alpha$, $\gamma, \delta, \phi$, and $\psi$.

The physical interpretation of each of the dimensionless groups $\delta, \phi$ and $\psi$, which directly influence the energy transfer, lies in their definitions of [25d] to [25f]. Multiplying both the numerator and the denominator of the right-hand side of [25d] by $\mathrm{b}(\overline{\mathrm{T}-\theta})$ shows that $\delta$ is the ratio between the average amount of heat transferred to a unit mass of grain passing through the dryer and the amount of heat required to raise the temperature of that mass from the average temperature of the grain in the dryer $(\bar{\theta})$ to the average temperature of the air in the dryer $(\overline{\mathrm{T}})$.

Taking a similar approach to Equation [25f], multiplying both the numerator and the denominator by $\mathrm{L}(\overline{\mathrm{T}-\theta})$, shows $\psi$ to be the ratio between the average amount of heat released by a unit mass of air passing through the dryer and the heat released by that mass when cooled from $\overline{\mathrm{T}}$ to $\bar{\theta}$.

Both $\delta$ and $\psi$ relate the total energy transferred between the gas and the solid phases in the dryer to sensible heats associated with these phases. Based on the ratio $\delta / \psi$ and the temperatures $\overline{\mathrm{T}}_{\text {out }}{ }^{*}$ (s.s) and $\bar{\theta}_{\text {out }}{ }^{*}$ (s.s), one can estimate the relative importance of the two energy-consuming processes in the dryer: the evaporation of water and heating of grain. Substituting $\overline{\mathrm{T}^{*}-\theta^{*}}$ from [36], one can write [25d] as

$$
\frac{\mathrm{h} \mathrm{L}(\overline{\mathrm{T}-\theta})}{\mathrm{G}_{\mathrm{p}}(0) \mathrm{C}_{\mathrm{pg}}\left(\bar{\theta}_{\text {out }}(\mathrm{s} . \mathrm{s})-\bar{\theta}_{\text {in }}(0)\right)}=\frac{\delta}{\psi} \frac{1-\overline{\mathrm{T}}_{\text {out }}{ }^{*}(\mathrm{~s} . \mathrm{s})}{\bar{\theta}_{\text {out }}{ }^{*}(\mathrm{~s} . \mathrm{s})} \text {. }
$$

The left-hand side of Equation [40] is the ratio between the total heat transferred from the air to a unit mass of grain in the dryer and the heat consumed in raising its temperature while passing through the dryer. As this ratio increases, so does the fraction of energy transferred between phases going to drying (evaporating water rather than heating grain). Typical values for $\delta$ and $\psi$ are 30 and 20, respectively.

$\phi$, defined in [25e], is the ratio between the latent heat needed to evaporate all the water contained in a portion of grain in the feed and the sensible heat needed to raise the temperature of this portion to that of the air feed. $\phi$ approximates, but not necessarily fulfills, the relative energy requirements of the two processes taking place in the dryer: drying and heating. $\phi$ in typical dryers ranges in value from 10 to 20 . 
$\beta$, defined in [25b], is the ratio between the residence time of the grain and the residence time of the air. It does not affect the steady-state, but has a great influence on the dynamics of the system. $\beta$ directly affects the time derivatives of the dimensionless humidity and temperature of the air (Equations [22] and [24]), and indirectly affects the time derivatives for the grain (through $\mathrm{R}^{*}$ and $\mathrm{T}^{*}$; see Equations [21] and [23]). Typically the value of $\beta$ is on the order of several thousand. It has some implications that will be discussed later at length:

1. The changes in $\mathrm{W}^{*}$ and $\mathrm{T}^{*}$ are much faster than the changes in $\mathrm{M}^{*}$ and $\theta^{*}$.

2. Mathematically, the system of Equations [21] to [24] is stiff.

3. In conditions of moderate changes in the feed to the dryer, air may assume a quasi-steady state (ignore the accumulation terms).

\section{Numerical Example}

An example of the analysis made in the previous section follows. The data for the dryer dimensions and conditions of operation belong to a commercial dryer used for experiments by personnel from the Agricultural Engineering Department at University of California, Davis (see table 1).

$R_{c}$ and $h(0)$ are found, using the empirical correlations in Equations [8] and [12], respectively:

$$
\mathrm{R}_{\mathrm{c}}=2.344 \cdot 10^{-5} \quad \mathrm{~h}(0)=2.777 \cdot 10^{4} .
$$

At this stage, the six dimensionless groups characterizing the dryer may be calculated, using Equations [25a] to [25f]:

$$
\begin{array}{ll}
\alpha=0.153 & \delta=32.89 \\
\beta=3403 & \phi=17.21 \\
\gamma=1.052 & \psi=18.61 .
\end{array}
$$

The numerical solution of the model, with the corresponding parameters and inlet conditions, yields the steady-state distributions of the moisture, humidity, and temperatures in the dryer, as well as their average values at the outlets. (The method used to solve the model will be discussed later.)

TABLE 1. DATA USED FOR DRYER USED IN THE SIMULATIONS

\begin{tabular}{llll}
\hline \hline $\mathrm{L}$ & $=21.3$ & & $\mathrm{H}_{\mathrm{w}}-\mathrm{h}_{\mathrm{w}}=2.326 \cdot 10^{6}$ \\
$\mathrm{~b}$ & $=0.28$ & $\mathrm{M}_{\mathrm{in}}$ & $=0.228$ \\
$\epsilon$ & $=0.57$ & $\mathrm{~W}_{\mathrm{in}}$ & $=0.009$ \\
$\rho_{\mathrm{a}}$ & $=1.13$ & $\theta_{\text {in }}$ & $=36.11$ \\
$\rho$ & $=1394$ & $\mathrm{~T}_{\mathrm{in}}$ & $=50.83$ \\
$\mathrm{C}_{\mathrm{pa}}$ & $=1005$ & $\mathrm{G}_{\mathrm{p}}$ & $=8.588$ \\
$\mathrm{C}_{\mathrm{pg}}$ & $=2094$ & $\mathrm{G}_{\mathrm{a}}$ & $=0.4157$ \\
\hline
\end{tabular}


The average values at steady-state are

$$
\begin{array}{ll}
\overline{\mathrm{M}}_{\text {out }}{ }^{*}(\mathrm{~s} . \mathrm{s})=0.8991 & \bar{\theta}_{\text {out }}{ }^{*}(\mathrm{~s} . \mathrm{s})=0.3300 \\
\overline{\mathrm{W}}_{\text {out }}{ }^{*}(\mathrm{~s} . \mathrm{s})=1.6945 & \overline{\mathrm{T}}_{\text {out }}{ }^{*}(\mathrm{~s} . \mathrm{s})=-0.1695 .
\end{array}
$$

The distribution of the variables in the dryer is represented by dividing the dryer into 14 rows and 14 columns (see table 2). For each of the 196 compartments thus formed, we can assume that the properties of the rice and the air are uniform. Rows 1 and 14 correspond to the rice inlet and outlet, respectively, while columns 1 and 14 correspond to the air inlet and outlet, respectively.

Each compartment in table 2 is represented by the values of the four dimensionless variables $\left(\mathrm{M}^{*}, \theta^{*}, \mathrm{~W}^{*}, \mathrm{~T}^{*}\right)$ and corresponding rate of drying $\left(\mathrm{R}^{*}\right)$. Moving along a row gives the distribution along the $\mathrm{x}$ axis for a constant $\mathrm{y}$ (defined by the row number). Similarly, moving down a column gives the distribution along the y axis for a constant $\mathrm{x}$ (defined by the column number).

Table 2 shows that along the $\mathrm{x}$ direction of the dryer, $\mathrm{M}$ and $\mathrm{W}$ increase while $\theta$ and $\mathrm{T}$ decrease. Along the $\mathrm{y}$ direction, $\mathrm{M}$ decreases and $\mathrm{W}$ has a maximum, while $\theta$ and $\mathrm{T}$ demonstrate more complicated behavior. They increase monotonically at the side closer to the air inlet, but have minima while approaching the air outlet. Figures 2 through 6 demonstrate the behavior of these variables. The discretization of the spatial coordinates for numerical solution requires careful interpretation of the data points on the plots. Each compartment expresses the spatial distribution of the variables as it translates into one point corresponding to the center of the compartment.

Some of these phenomena can be explained simply by examining Equations [21] to [24], after substituting zero for the time derivatives. These equations show that $\partial \mathrm{W} / \partial \mathrm{x}$ is positive while $\partial \mathrm{M} / \partial \mathrm{y}$ and $\partial \mathrm{T} / \partial \mathrm{x}$ are negative (assuming $\mathrm{T}-\theta$ is positive). $\partial \theta / \partial \mathrm{y}$ at steady-state is the difference of two positive terms and may be either positive or negative. Equations [21] and [22] can give us some idea about the behavior of $\partial M / \partial x$ and $\partial W / \partial y$. If we assume uniform feeds, then $M$ at $y=0$ is the same for all $x(\partial M / \partial x=0)$, and $W$ at $x=0$ is the same for all $y(\partial W / \partial y=0)$. Derivation of Equation [21] in relation to $x$, assuming steady-state, gives

$$
\frac{\partial}{\partial \mathrm{y}^{*}}\left(\frac{\partial \mathrm{M}^{*}}{\partial \mathrm{x}^{*}}\right)=-\alpha \frac{\partial \mathrm{R}^{*}}{\partial \mathrm{x}^{*}} \text {. }
$$

Equation [41] and the uniform moisture of the grain in the feed lead us to the conclusion that $\partial \mathrm{M} / \partial \mathrm{x}$ near the grain inlet (close to $\mathrm{y}=0$ ) has the opposite sign to that of $\partial \mathrm{R} / \partial \mathrm{x}$.

$\mathrm{R}$ itself increases with $\mathrm{M}, \theta$, and $\mathrm{T}$ and decreases with $\mathrm{W}$ (Equations [8] to [11]). Examining the behavior of $\mathrm{M}, \theta, \mathrm{W}$, and $\mathrm{T}$ along the $\mathrm{x}$ direction, reveals that $\mathrm{M}$ tends to increase $R$ in that direction (but at least near $y=0, M$ cannot succeed due to Equation [41]), whereas $\theta, \mathrm{W}$, and $\mathrm{T}$ tend to decrease it. In the whole dryer, $\mathrm{R}$ decreases with $\mathrm{x}$, which means that $\mathrm{M}$ does not play a dominant role in determining the trend of $\mathrm{R}$ along the $\mathrm{x}$ direction. Instead, $\mathrm{M}$ agrees with its relatively moderate variation along that direction (changes in $M$ are larger along the $y$ direction). The opposite trends of $\mathrm{M}$ and $\mathrm{R}$ along the $\mathrm{x}$ direction near the grain inlet, as determined by Equation [41], are induced by the boundary $y=0$ to the whole dryer: $M$ increases with $x$, while $\mathrm{R}$ decreases. 


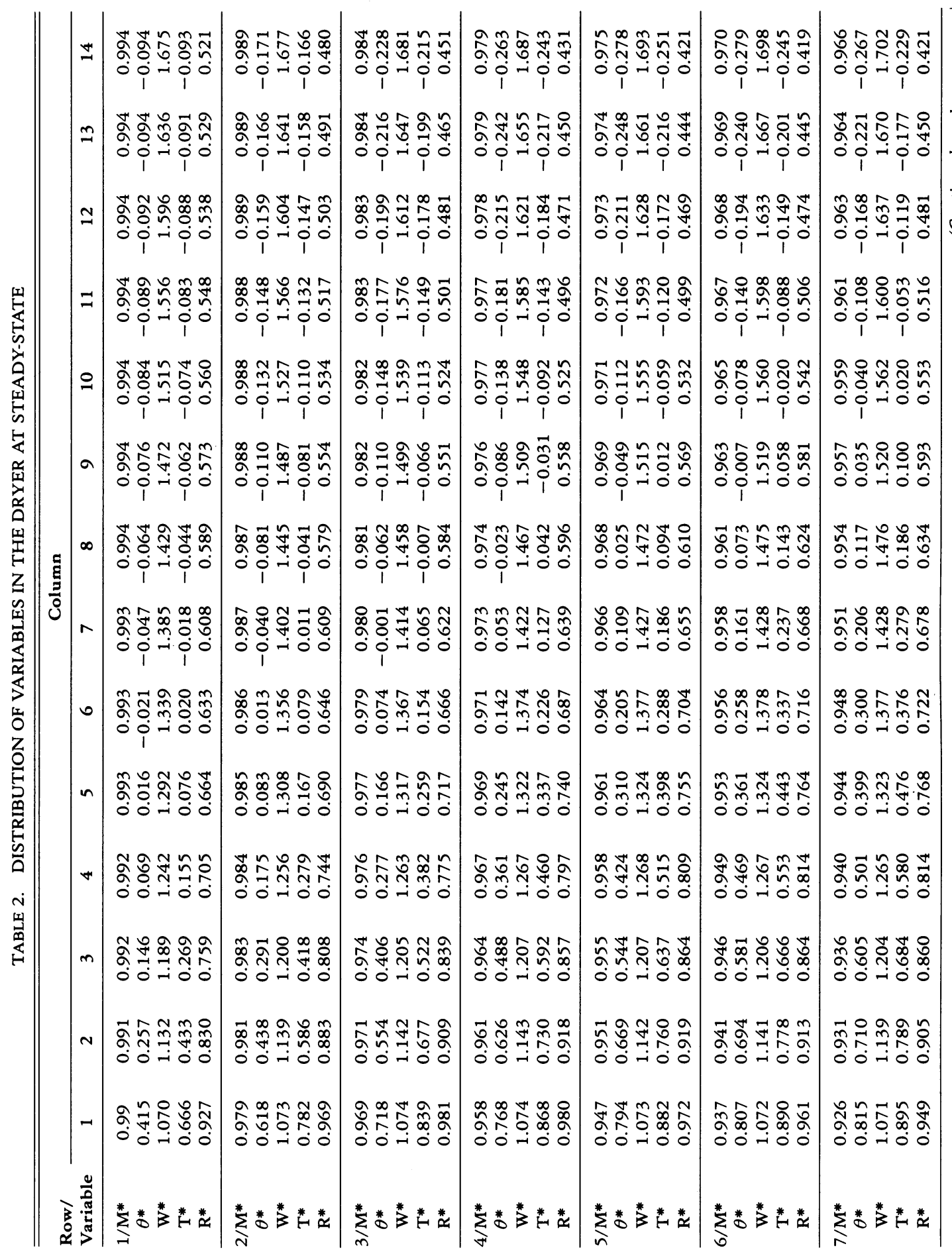




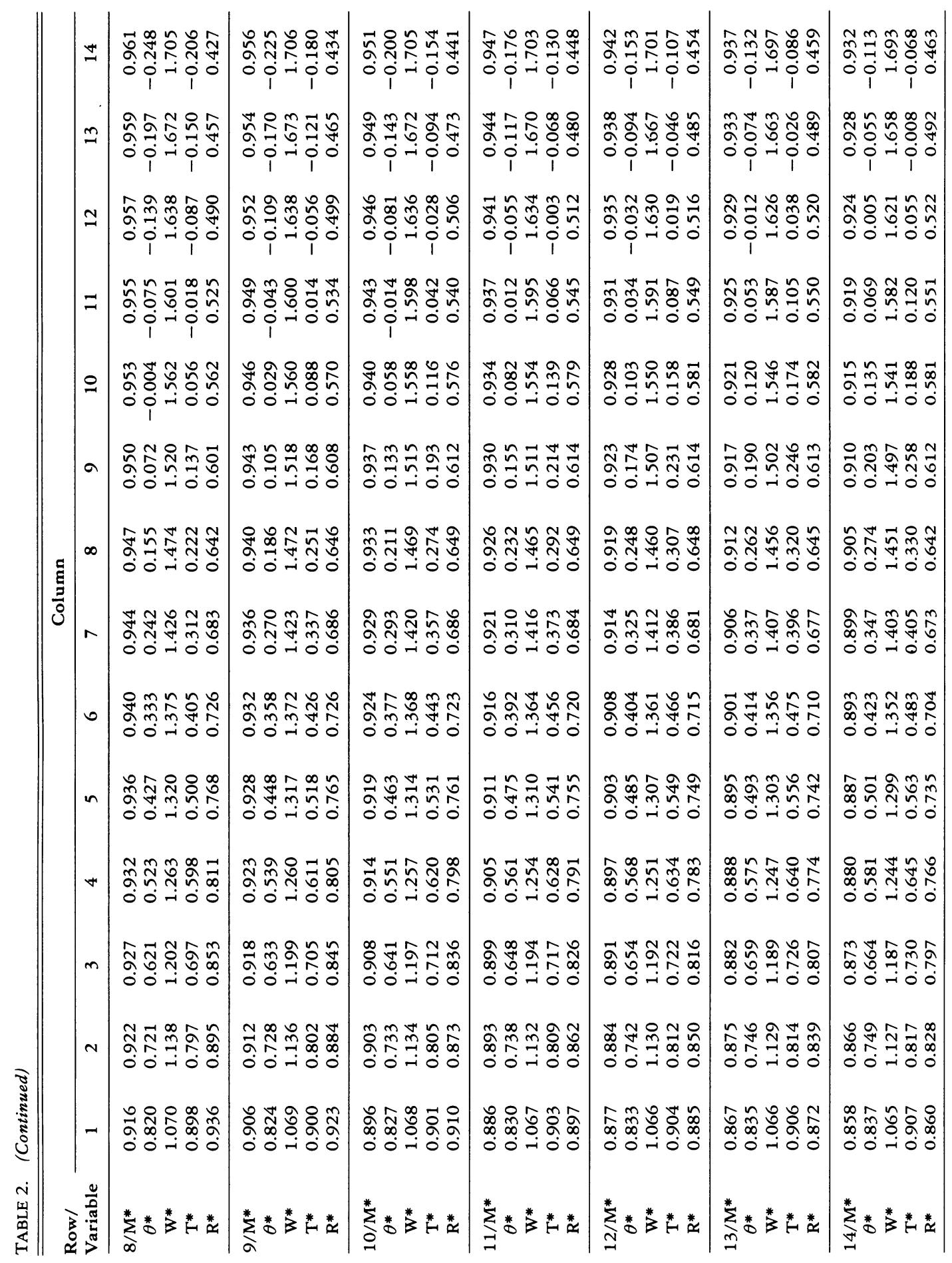




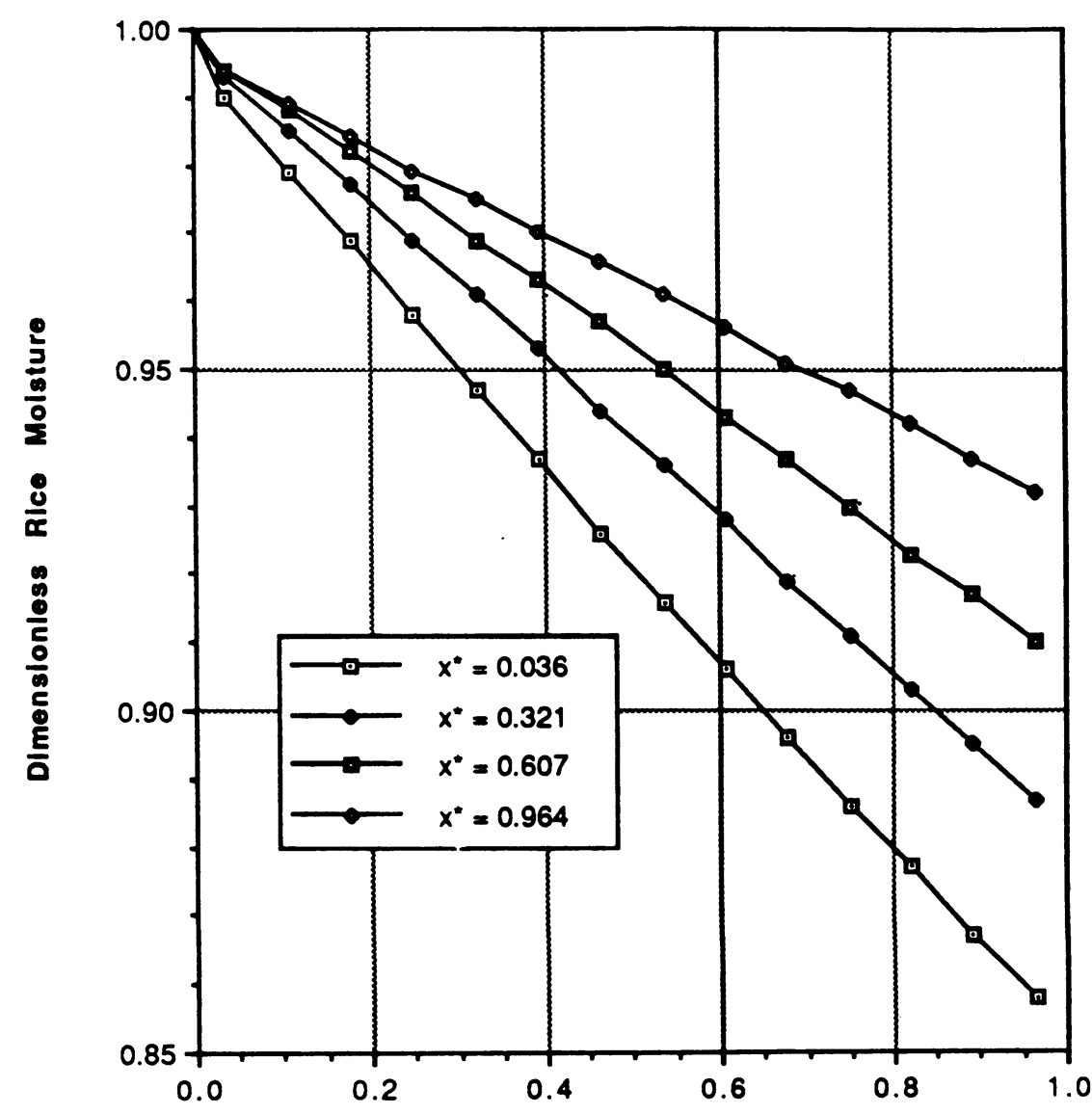

Dimensionless Longth

Fig. 2. Steady-state rice moisture profiles.

In an analogous manner to the derivation of Equation [41], the following equation for the steady-state may be derived from Equation [22]:

$$
\frac{\partial}{\partial \mathrm{x}^{*}}\left(\frac{\partial \mathrm{W}^{*}}{\partial \mathrm{y}^{*}}\right)=-\alpha \frac{\partial \mathrm{R}^{*}}{\partial \mathrm{y}^{*}}
$$

Due to the uniform humidity of the air in the feed, Equation [42] determines that near the air feed $\mathrm{W}$ and $\mathrm{R}$ have the same trend along the $\mathrm{y}$ direction. Thus, when $\mathrm{W}$ and $\mathrm{R}$ approach $\mathrm{y}=0, \mathrm{~W}$ is not dominant in determining the trend of $\mathrm{R}$ along the 


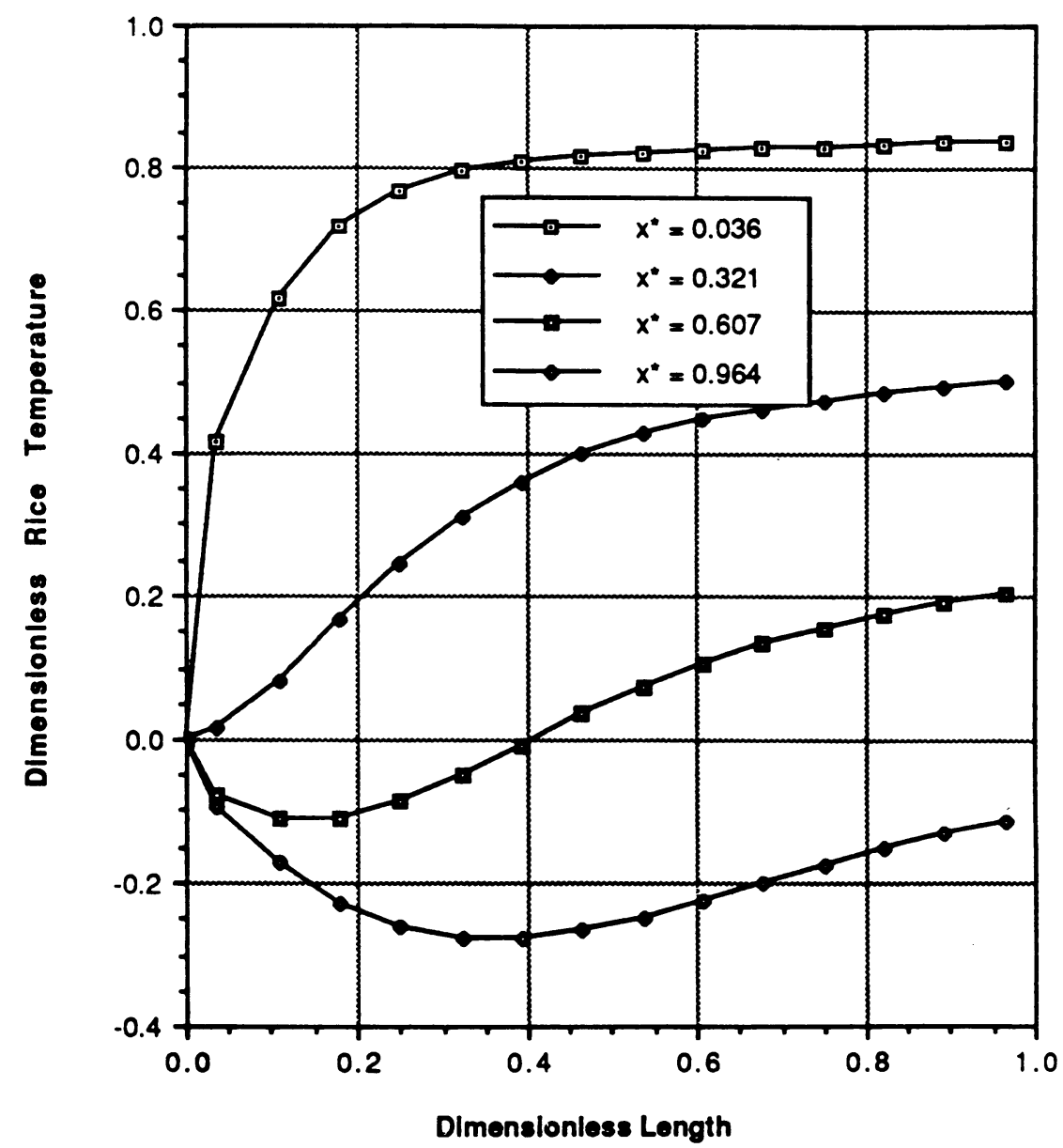

Fig. 3. Steady-state rice temperature profiles.

$\mathrm{y}$ direction ( $\mathrm{W}$ influences the trend of $\mathrm{R}$ in an opposite direction to its own trend; see Equations [8] to [11]). In this case, $\mathrm{W}$ agrees with its relatively moderate variation along that direction (changes in $\mathrm{W}$ are considerably larger along the $\mathrm{x}$ direction). Along the $\mathrm{y}$ direction, close to the air inlet, $\theta$ and $\mathrm{T}$ tend to raise $\mathrm{R}$ while $\mathrm{M}$ tends to lower it. These opposing trends cause a maximum in $\mathrm{R}$, which dictates a maximum in $\mathrm{W}$ exactly at the same spot because of Equation [42] (row 3 and column 1 in table 2). This phenomenon of maximum in $\mathrm{W}$ is induced when $\mathrm{y}=0$ to the inside of the dryer. The nonuniform trend of $\mathrm{R}$ along the $\mathrm{y}$ direction is not specific only to the region close to the air inlet, but manifests itself along each longitudinal cross-section of the dryer. 


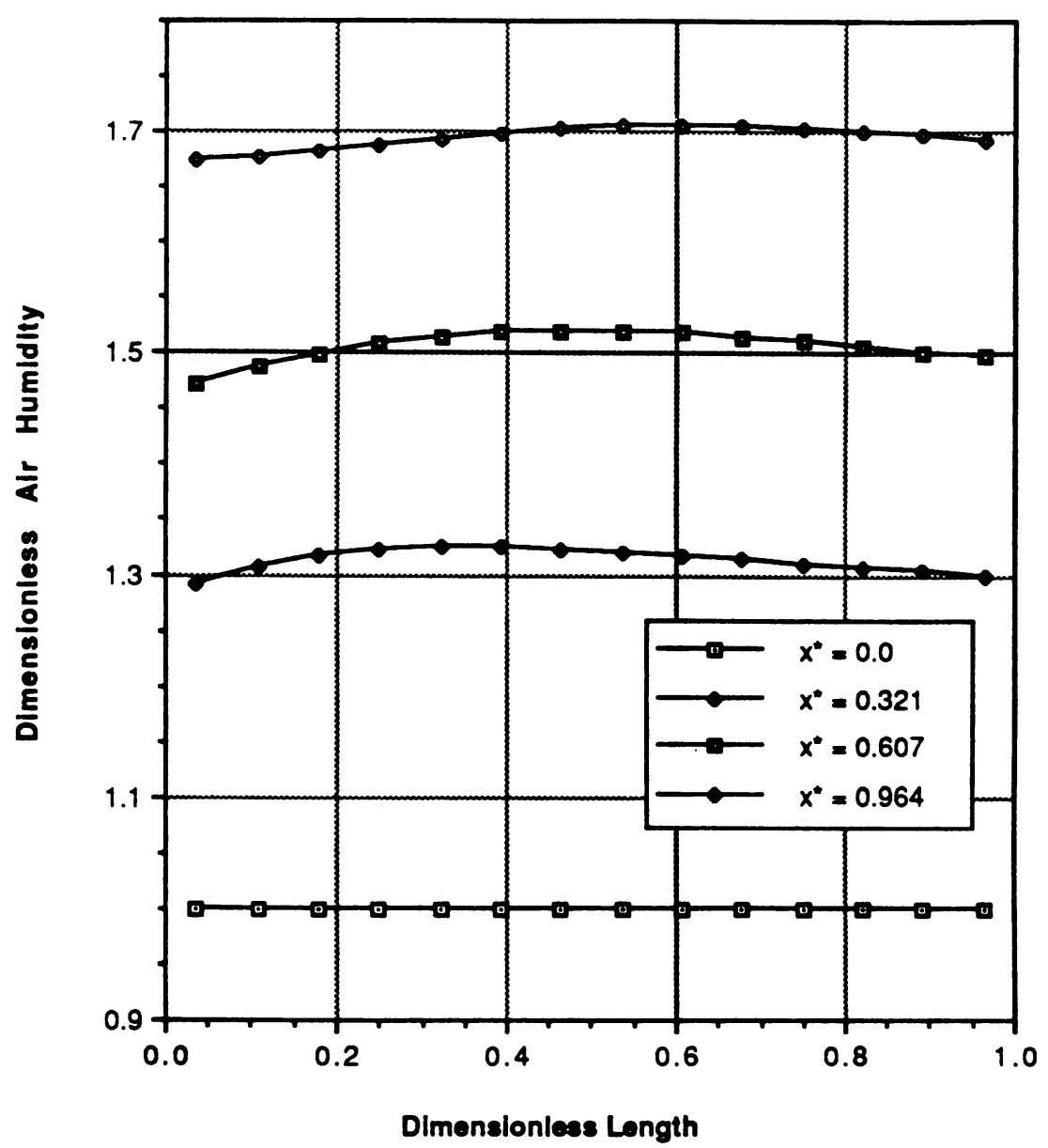

Fig. 4. Steady-state air humidity profiles.

$\mathrm{R}$ shows a maximum near the air inlet, a minimum near the air outlet and both a maximum and a minimum in the middle of the dryer.

Towards the air outlet, $\theta$ and $\mathrm{T}$ exhibit a minimum along the $\mathrm{y}$ direction. From Equation [23], we find that, at steady-state, $\partial \theta^{*} / \partial y^{*}$ is a difference between two positive terms, one of which is proportional to $\mathrm{R}^{*}$. Close to the air outlet, this difference crosses zero along the $y$ direction. This is understandable, considering the nonuniform trend of $\mathrm{R}$ in that direction. When zero is substituted for the time derivatives, the behavior of $\mathrm{T}$ at steady-state is coupled with that of $\theta$ through Equations [23] and [24]. In the above region, near the air outlet, $M$ changes more moderately with $\mathrm{y}$, so $\theta$ and $\mathrm{T}$ 


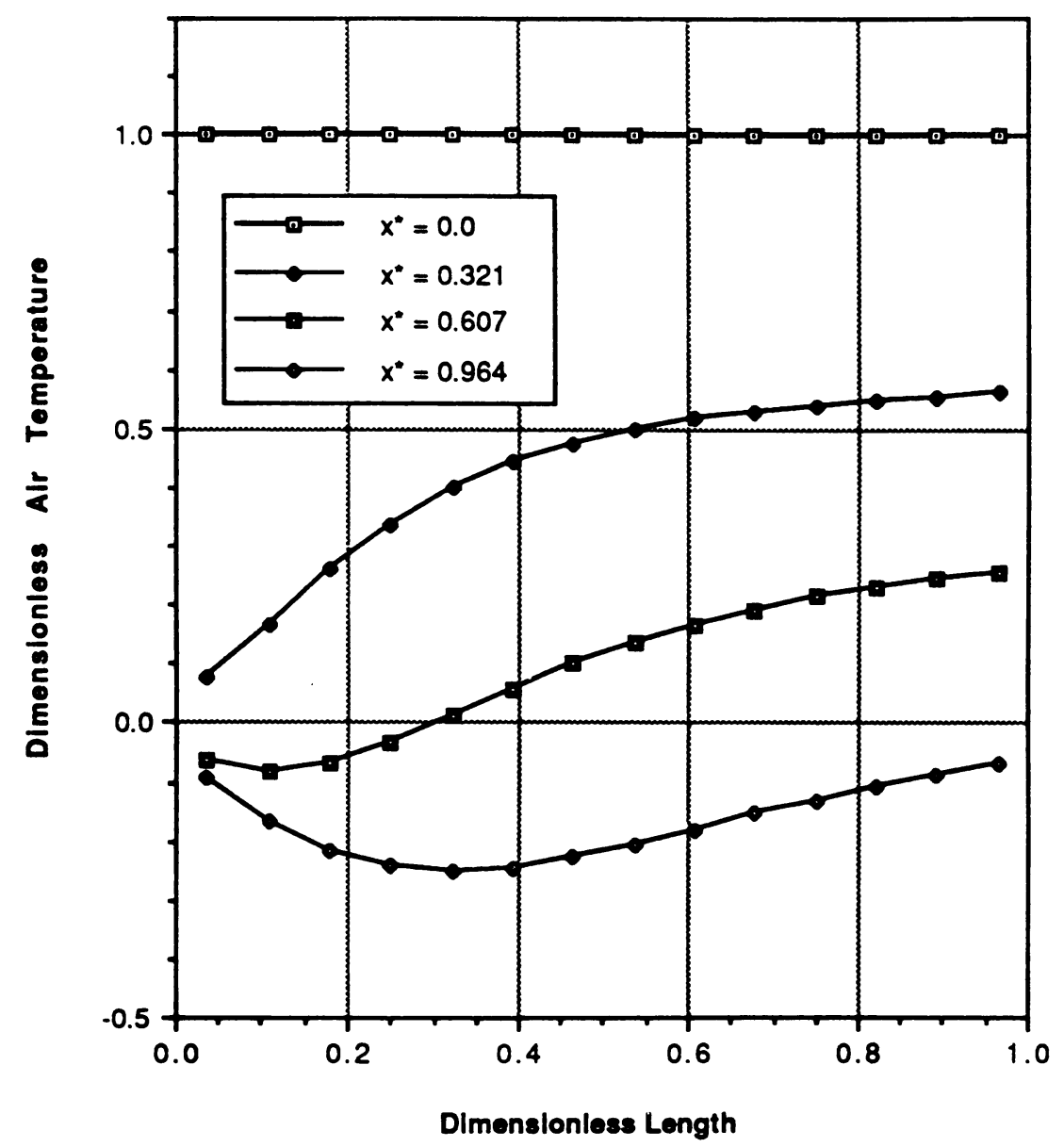

Fig. 5. Steady-state air temperature profiles.

seem to dominate the determination of the trend of $\mathrm{R}$ along the $\mathrm{y}$ direction. Examination of the last few columns on the right-hand side of table 2 reveals that, indeed, for a given $\mathrm{y}$ the minima for $\theta$ and $\mathrm{T}$ are very close to the minimum for $\mathrm{R}$.

Note that $R_{c}$, which represents the characteristic drying rate at the intersection of the $\mathrm{x}$ and $\mathrm{y}$ axes, is not the maximum rate of drying (as one mistakenly can think because at this point, fresh air meets the wettest grain). At $x=0$, a range of y's corresponds to slightly higher rates than $R_{c}$, because of the higher rice temperature. According to Equations [8] to [11], $\mathrm{R}$ increases with $\mathrm{M}, \theta$, and $\mathrm{T}$ and decreases with W. 


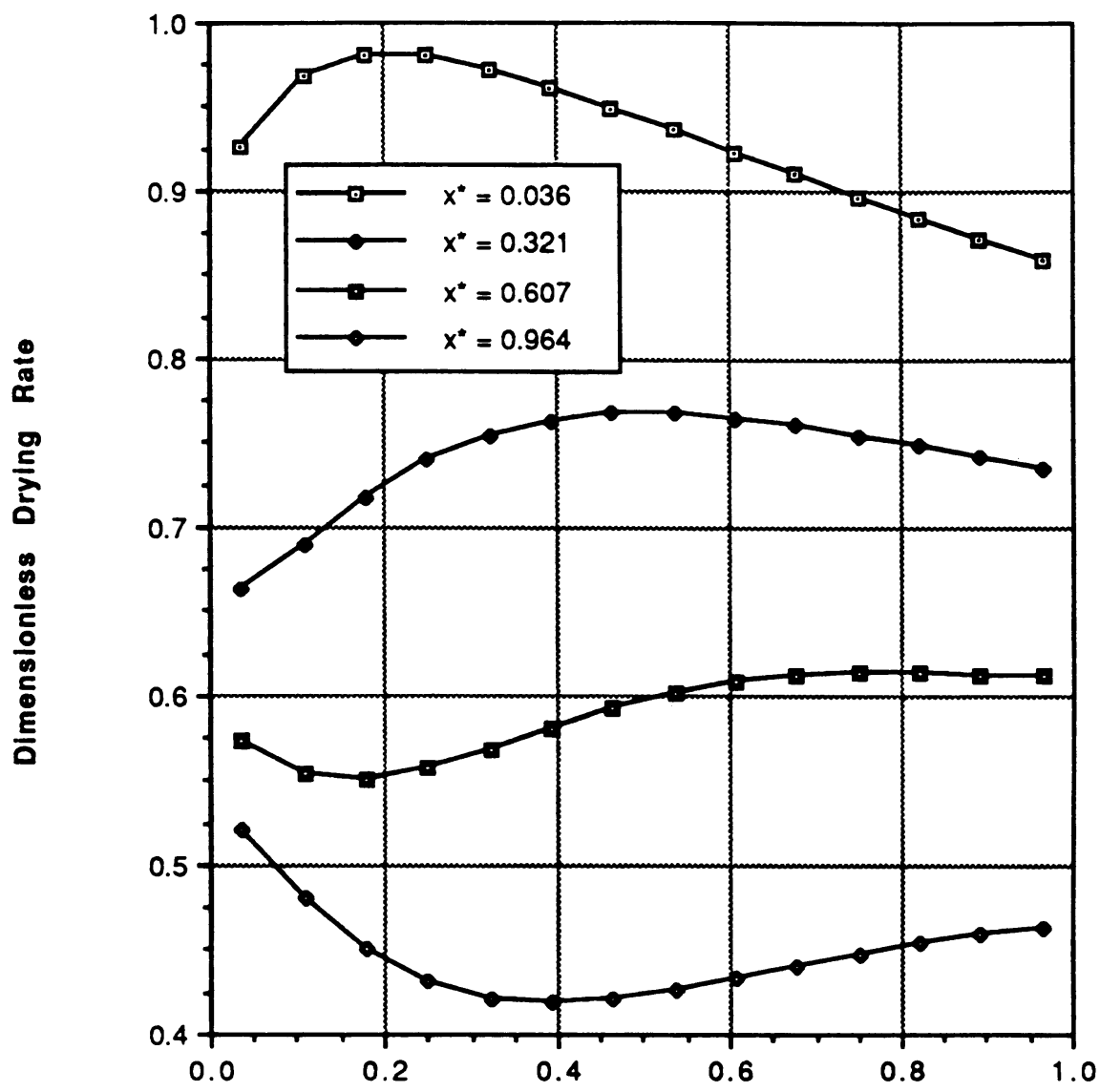

Dimensionless Length

Fig. 6. Steady-state rice drying rate profiles.

A notable phenomenon is the decrease of both $\theta^{*}$ and $\mathrm{T}^{*}$ below zero in the region close to the air outlet. This means that the highly endothermic drying process causes the temperature of both the rice and the air towards the air outlet to be lower than the temperature of the rice in the feed.

The six dimensionless groups give us information about average values of the transfer rates inside the dryer and of the properties at its outlets. $\overline{\mathrm{R}}^{*}{ }_{\text {s.s }}$ is found to be 0.66 (either from Equation [31] or [33]). As $\overline{\mathrm{R}}^{*}{ }_{\text {s.s }}$ is generally smaller than 1, we could not expect to get $\overline{\mathrm{M}}_{\text {out }}{ }^{*}$ (s.s) smaller than 0.847 from this dryer before solving the model. 
The way to improve the drying for a given rice is by raising $\alpha$ by one or more of the following:

1. Increasing the dryer length $\mathrm{L}$.

2. Increasing the characteristic rate of drying $R_{c}$ (by raising the air temperature and/or lowering its humidity).

3. Lowering the mass velocity of the grain $G_{p}$.

$\mathrm{T}^{*}-\theta^{*}$, the average temperature difference between the air and the rice in the dryer, is found from either Equation [35] or [36] to be 0.0628 (equivalent to $0.925^{\circ} \mathrm{C}$ ). This small difference is due to high values of either $\delta$ or $\psi$, caused by a relatively large $\mathrm{h}$ (in relation to $\mathrm{G}_{\mathrm{p}} \mathrm{C}_{\mathrm{pg}} / \mathrm{L}$ and to $\mathrm{G}_{\mathrm{a}} \mathrm{C}_{\mathrm{pa}} / \mathrm{b}$ ). As the values of $\delta$ and $\psi$ in our example are quite typical, we may expect small $\mathrm{T}^{*}-\theta^{*}$ 's in other commercial dryers as well.

The average rate for the interphase heat transfer in the dryer per unit depth is given by hbL $(\overline{\mathrm{T}-\theta})$ and equals $1.531 \cdot 10^{5} \mathrm{~J} / \mathrm{sec}$. The ratio between the total heat transferred to the grain in the dryer and the enthalpy gained by the grain, while passing through the dryer, is expressed by the right-hand side of Equation [40] in terms of $\delta / \psi$, $\overline{\mathrm{T}}_{\text {out }}{ }^{*}(\mathrm{~s} . \mathrm{s})$, and $\bar{\theta}_{\text {out }}{ }^{*}$ (s.s). In our example, this ratio is found to be 6.26 , which means that about $84 \%$ of the heat transferred is consumed by water evaporation.

As a general conclusion of our discussion, one may estimate the orders of magnitude of the spatial derivatives at the right hand sides of Equations [21] to [24] at steadystate. By substituting 1 for $\mathrm{R}^{*}, 0.1$ for the difference $\mathrm{T}^{*}-\theta^{*}$, and typical values for $\alpha$, $\gamma, \delta, \phi$, and $\psi(0.1,1,30,15$, and 20 , respectively $)$, we get

$$
\begin{aligned}
& O\left[\frac{\partial \mathrm{M}^{*}}{\partial \mathrm{y}^{*}}\right]=-0.1, \\
& \mathrm{O}\left[\frac{\partial \mathrm{W}^{*}}{\partial \mathrm{x}^{*}}\right]=+1, \text { and } \\
& \mathrm{O}\left[\frac{\partial \mathrm{T}^{*}}{\partial \mathrm{x}^{*}}\right]=-1,
\end{aligned}
$$

with the signs showing the direction of the variation.

After the above substitutions, a difference between two positive terms of order of magnitude 1 is obtained for $\partial \theta^{*} / \partial y^{*}$. This difference is sensitive to variations in $\delta$, $\mathrm{T}^{*}-\theta^{*}, \alpha, \phi$, and $\mathrm{R}^{*}$. As seen in our example, this term is generally positive, but it may be negative close to the air outlet.

The dimensionless group $\beta$, which is more than 3,000 in our example, has no affect on the steady-state distributions shown in table 2 , but plays an important role in the dynamic response of the dryer, which will be discussed in the following sections.

\section{3 \\ NUMERICAL SOLUTIONS}

\section{Lumping Procedure}

To solve the model equations numerically, the dryer is divided into $N_{R}$ rows and $N_{C}$ columns (see fig. 7). The choice of $N_{R}$ and $N_{C}$ will be discussed later. This division 


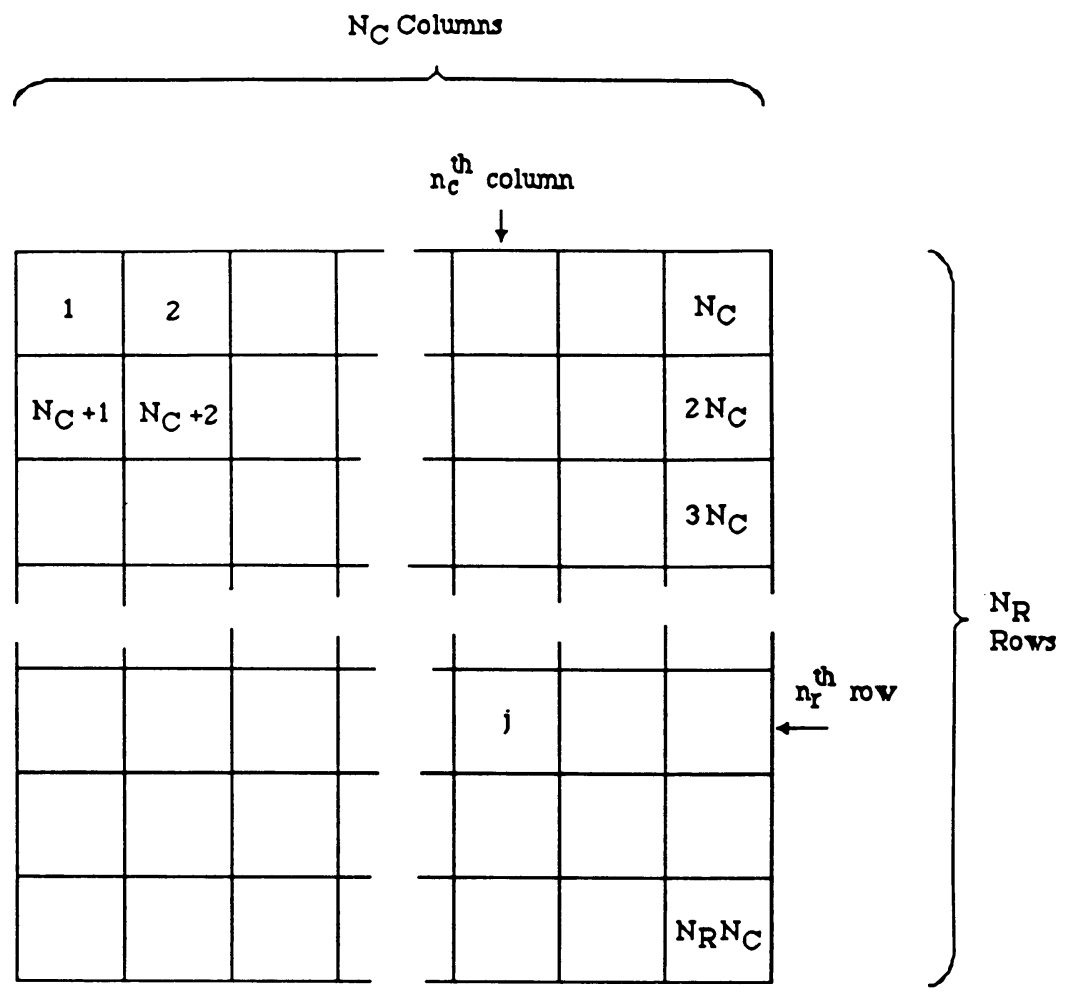

Fig. 7. Division of the dryer into compartments.

forms $\mathrm{N}_{\mathrm{R}} \cdot \mathrm{N}_{\mathrm{C}}$ compartments, and we assume that in each of them the properties of both the grain and the air are uniform.

Each compartment has an index $\mathrm{j}$ according to its location in the dryer. The compartment in the $n_{r}{ }^{\text {th }}$ row and in the $n_{c}{ }^{\text {th }}$ column (number of column increases with $x$ ) has an index $\mathrm{j}$ given by

$$
\mathrm{j}=\left(\mathrm{n}_{\mathrm{r}}-1\right) \mathrm{N}_{\mathrm{C}}+\mathrm{n}_{\mathrm{c}} .
$$

The spatial derivatives in the model equations are discretized using finite differences. The partial derivative of a dimensionless variable $\mathrm{V}^{*}$ (in our case, $\mathrm{W}^{*}$ or $\mathrm{T}^{*}$ ) with respect to $x^{*}$ is approximated by

$$
\begin{aligned}
& \frac{\partial V_{j}^{*}}{\partial x^{*}} \simeq N_{C}\left(V_{j}^{*}-V_{j-1}{ }^{*}\right), \text { for } \operatorname{MOD}\left(j-1, N_{C}\right)>0 \text { and } \\
& \frac{\partial V_{j}^{*}}{\partial x^{*}} \simeq N_{C}\left(V_{j}^{*}-V_{i n}^{*}\left(j, t^{*}\right)\right), \text { for } \operatorname{MOD}\left(j-1, N_{C}\right)=0,
\end{aligned}
$$


where $V_{\text {in }}{ }^{*}\left(j, t^{*}\right)$ denotes the value of $V^{*}$ in the feed. In the general case, the feed changes with time and with the location along the $y$ axis.

A similar approximation may be written for the derivative of a variable $U^{*}$ with respect to $\mathrm{y}^{*}$ :

$$
\begin{aligned}
& \frac{\partial U_{j}^{*}}{\partial y^{*}} \simeq N_{R}\left(U_{j}^{*}-U_{j-N{ }^{*}}\right), \text { for } j>N_{C} \text { and } \\
& \frac{\partial U_{j}^{*}}{\partial y^{*}} \simeq N_{R}\left(U_{j}^{*}-U_{i n}^{*}\left(j, t^{*}\right)\right), \text { for } j \leq N_{C},
\end{aligned}
$$

where $U_{\text {in }}{ }^{*}\left(j, t^{*}\right)$ denotes the value of $U^{*}$ in the feed and may change with time and with the location along the $\mathrm{x}$ axis.

The discretization of the spatial derivatives in the model, Equations [21] to [24], yields a system of $4 \cdot N_{R} \cdot N_{C}$ coupled ODEs with time as the only dependent variable. This technique is called the Method of Lines (MOL) (Davis, 1984).

\section{Stiffness Analysis}

For analyzing the stiffness of the system of ODEs thus formed, consider the case in which the initial conditions are chosen to be uniform distributions of all the variables with values that correspond to the inlet conditions, that is, $\mathbf{M}_{\mathrm{j}}^{*}(0)=1, \theta_{\mathrm{j}}^{*}(0)=1$, $\mathrm{W}_{\mathrm{j}}{ }^{*}(0)=1$, and $\mathrm{T}_{\mathrm{j}}{ }^{*}(0)=1$ for ${ }_{\mathrm{j}}=1,2, \ldots, \mathrm{N}_{\mathrm{R}} \mathrm{N}_{\mathrm{c}}$. Next, we compute the derivatives $\frac{\mathrm{dM}_{\mathrm{i}}^{*}}{\mathrm{dt}^{*}}, \frac{\mathrm{dW}^{*}}{\mathrm{dt}^{*}}, \frac{\mathrm{d} \theta^{*}}{\mathrm{dt}^{*}}$, and $\frac{\mathrm{dT}_{\mathrm{j}}^{*}}{\mathrm{dt}}$. Remembering that $\mathrm{G}_{\mathrm{p}}^{*}(0)=\mathrm{G}_{\mathrm{a}}^{*}(0)=\mathrm{h}^{*}(0)=1$ by definition and noting that $R_{j}^{*}(0)=1$ in this case for all $j$ 's, from Equations [21] to [24] we get

$$
\begin{aligned}
& \frac{\mathrm{dM}_{\mathrm{j}}^{*}}{\mathrm{dt}^{*}}(0)=-\alpha, \\
& \frac{\mathrm{dW}_{\mathrm{j}}^{*}}{\mathrm{dt}^{*}}(0)=\beta \gamma, \\
& \frac{\mathrm{d} \theta_{\mathrm{j}}^{*}}{\mathrm{dt}^{*}}(0)=\delta-\alpha \phi, \text { and } \\
& \frac{\mathrm{dT}_{\mathrm{j}}^{*}}{\mathrm{dt}^{*}}(0)=-\beta \psi .
\end{aligned}
$$

Therefore, the ratio between the rates of change of the dimensionless air humidity and the grain moisture at $t^{*}=0$ is given by

$$
\mathrm{r}_{\mathrm{W}^{*} \mathrm{M}^{*}}(0)=-\frac{\beta \gamma}{\alpha},
$$

and the ratio between the rates of change of the dimensionless temperatures of the air and the grain at $t^{*}=0$ is given by

$$
\mathrm{r}_{\mathrm{T}^{*} \theta^{*}}(0)=-\frac{\beta \psi}{\delta-\alpha \phi} .
$$


Although the ratios computed in Equations [47a] and [47b] correspond to a specific situation, they may serve as indicators for the order of magnitude of such ratios in general. As typical values for $\alpha, \gamma, \delta, \phi$, and $\psi$ are $0.1,1,30,15$, and 20 , respectively, $\mathrm{O}\left[\mathrm{r}_{\left.\mathrm{W}^{*} \mathrm{M}^{*}\right]}=\mathrm{O}[10 \beta]\right.$, while $\mathrm{O}\left[\mathrm{r}_{\left.\mathrm{T}^{*} \theta^{*}\right]}=\mathrm{O}[\beta]\right.$. Thus, the dynamic changes in the air are faster than those in the grain by a factor of $O[\beta]$ or more. As the value of $\beta$ is typically some thousands, the system of the $4 \cdot N_{R} \cdot N_{C}$ ODEs, representing the PDEs [21] to [24], is stiff.

The mathematical model for the dryer was solved by a simulation program written in Advanced Continuous Simulation Language (ACSL) (Reference Manual, 1986). Because of the stiff character of the differential equations, Gear's Stiff Integration Method was used.

\section{The Mesh Influence}

Both the steady-state and the dynamic responses depend on the way the dryer is divided into mixed compartments, namely on $N_{R}$ and $N_{C}$. The same data (see table 1) are used for investigating the influence of $N_{R}$ and $N_{C}$ on the solution of the model equations. The influence on the steady-state is investigated first, and the results are summarized in table 3.

TABLE 3. THE MESH INFLUENCE ON THE STEADY-STATE VALUES OF THE DRYER OUTLETS, OBTAINED BY NUMERICAL SOLUTIONS

\begin{tabular}{lcccc}
\hline \hline Division & $\overline{\mathbf{M}}_{\text {out }}{ }^{*}(\mathbf{s . s .})$ & $\bar{\theta}_{\text {out }}{ }^{*}(\mathbf{s . s})$ & $\overline{\mathbf{W}}_{\text {out }}{ }^{*}(\mathrm{s.s})$ & $\overline{\mathbf{T}}_{\text {out }}{ }^{*}(\mathbf{s . s})$ \\
\hline $1 \times 8$ & 0.9036 & 0.2427 & 1.6634 & -0.0761 \\
$2 \times 8$ & 0.9017 & 0.2714 & 1.6764 & -0.1107 \\
$3 \times 8$ & 0.9011 & 0.2843 & 1.6806 & -0.1240 \\
$5 \times 8$ & 0.9006 & 0.2963 & 1.6840 & -0.1357 \\
$6 \times 8$ & 0.9005 & 0.2996 & 1.6849 & -0.1387 \\
$10 \times 8$ & 0.9002 & 0.3064 & 1.6866 & -0.1451 \\
$14 \times 8$ & 0.9001 & 0.3094 & 1.6874 & -0.1478 \\
\hline $8 \times 1$ & 0.9126 & 0.0875 & 1.6017 & +0.0990 \\
$8 \times 2$ & 0.9064 & 0.1908 & 1.6442 & -0.0195 \\
$8 \times 3$ & 0.9039 & 0.2359 & 1.6614 & -0.0694 \\
$8 \times 5$ & 0.9017 & 0.2776 & 1.6766 & -0.1146 \\
$8 \times 6$ & 0.9011 & 0.2890 & 1.6807 & -0.1268 \\
$8 \times 10$ & 0.8998 & 0.3130 & 1.6892 & -0.1525 \\
$8 \times 14$ & 0.8993 & 0.3239 & 1.6930 & -0.1640 \\
\hline $1 \times 1$ & 0.9156 & 0.0838 & 1.5809 & +0.1306 \\
$2 \times 2$ & 0.9077 & 0.1758 & 1.6351 & +0.0017 \\
$3 \times 3$ & 0.9046 & 0.2230 & 1.6563 & -0.0549 \\
$4 \times 4$ & 0.9030 & 0.2517 & 1.6676 & -0.0872 \\
$5 \times 5$ & 0.9019 & 0.2711 & 1.6748 & -0.1083 \\
$7 \times 7$ & 0.9007 & 0.2956 & 1.6832 & -0.1341 \\
$10 \times 10$ & 0.8997 & 0.3157 & 1.6899 & -0.1550 \\
$14 \times 14$ & 0.8991 & 0.3300 & 1.6945 & -0.1695 \\
\hline & & & &
\end{tabular}


The table is divided into three groups. The first group includes divisions of a constant $N_{C}\left(N_{C}=8\right)$ with different $N_{R}$ 's. The second group includes divisions of a constant $N_{R}\left(N_{R}=8\right)$ with different $N_{C}$ 's. The last group includes symmetrical divisions, where $N_{R}=N_{C}$.

Taking the finest division of $14 \times 14$ as a reference, table 3 reveals

1. As expected, a finer division in a given group yields better results.

2. For a given number of compartments the best results are obtained when $N_{C}>N_{R}$.

For example, the division $5 \times 8$ is better than $8 \times 5$, and even better than $7 \times 7$, which includes $22.5 \%$ more compartments. Thus, an optimal division, in terms of accuracy and computing time, should have a finer division in the direction of the air flow than in that of the grain flow because changes in the properties of air flowing through the dryer are relatively greater than those of the grain.

Comparison between the steady-state results obtained for the $5 \times 8$ and the $14 \times 14$ divisions suggests that the $5 \times 8$ mesh is sufficient for practical needs (see figs. 8 to 11 ). The relative differences in $\overline{\mathrm{M}}_{\text {out }}{ }^{*}$ (s.s) and $\overline{\mathrm{W}}_{\text {out }}{ }^{*}$ (s.s) are about $0.1 \%$ and $0.5 \%$, respectively, whereas the absolute differences in $\bar{\theta}_{\text {out }}{ }^{*}(\mathrm{~s} . \mathrm{s})$ and $\overline{\mathrm{T}}_{\text {out }}{ }^{*}(\mathrm{~s} . \mathrm{s})$ are about 0.035 , which correspond to a difference of about $0.5^{\circ} \mathrm{C}$. With a VAX $11 / 785$, the steady-state for the $5 \times 8$ mesh was found in less than 3 minutes of CPU time, using the 'TRIM' subcommand of ACSL, whereas the $14 \times 14$ mesh required about 35 minutes of CPU time.

To complete the comparison between the $5 \times 8$ and the $14 \times 14$ divisions, dynamic simulations are carried out for the dryer of table 1 with both divisions. The initial conditions for each simulation are chosen to be uniform distributions of all the variables with values that correspond to the inlet conditions:

$\mathrm{M}^{*}\left(\mathrm{x}^{*}, \mathrm{y}^{*}, 0\right)=1, \theta^{*}\left(\mathrm{x}^{*}, \mathrm{y}^{*}, 0\right)=0, \mathrm{~W}^{*}\left(\mathrm{x}^{*}, \mathrm{y}^{*}, 0\right),=1$ and $\mathrm{T}^{*}\left(\mathrm{x}^{*}, \mathrm{y}^{*}, 0\right)=1$. The simulations go up to $t^{*}=3(74.3$ minutes; the residence time of the grain is 24.78 minutes). Figures 8 to 11 describe the average properties of the grain and the air at the dryer outlets as a function of time for both mesh choices.

Examination of the above figures reveals that

1. At the beginning of the simulations, the responses for both meshes nearly coincide. This period lasts approximately half a unit of dimensionless time ( $\simeq 12 \mathrm{~min}$ ) for the grain properties and the air humidity (figs. 8 to 10), and approximately 0.2 units of dimensionless time ( $\simeq 5 \mathrm{~min}$ ) for the air temperature (fig. 11 ).

2. After these initial periods, the differences between the responses corresponding to different meshes increase. The differences between grain properties increase to maxima in $t^{*} \simeq 1(\simeq 25 \mathrm{~min})$ and afterwards decrease asymptotically to their values at steady-state. The differences in air humidity increase to values close to those corresponding to the steady-state and remain nearly constant.

3. The maximum difference between the curves for $\bar{M}_{\text {out }}{ }^{*}$ is about 0.008 $\left(\simeq 1.8 \cdot 10^{-3} \mathrm{~kg}\right.$ water $/ \mathrm{kg}$ dry rice $)$, and the maximum difference for $\bar{\theta}_{\text {out }}{ }^{*}$ is about $0.04\left(\simeq 0.6^{\circ} \mathrm{C}\right)$.

4. The steady-state differences in terms of dimensional variables, calculated from table 3 , are $2.3 \cdot 10^{-4} \mathrm{~kg}$ water $/ \mathrm{kg}$ dry rice for the grain moisture, $9 \cdot 10^{-5} \mathrm{~kg}$ water $/ \mathrm{kg}$ dry air for the air humidity, and about $0.5^{\circ} \mathrm{C}$ for the grain and air temperatures.

For most practical needs, the $5 \times 8$ mesh is sufficient, and the saving in computer time in relation to the $14 \times 14$ mesh is significant, especially with dynamic simulations. 


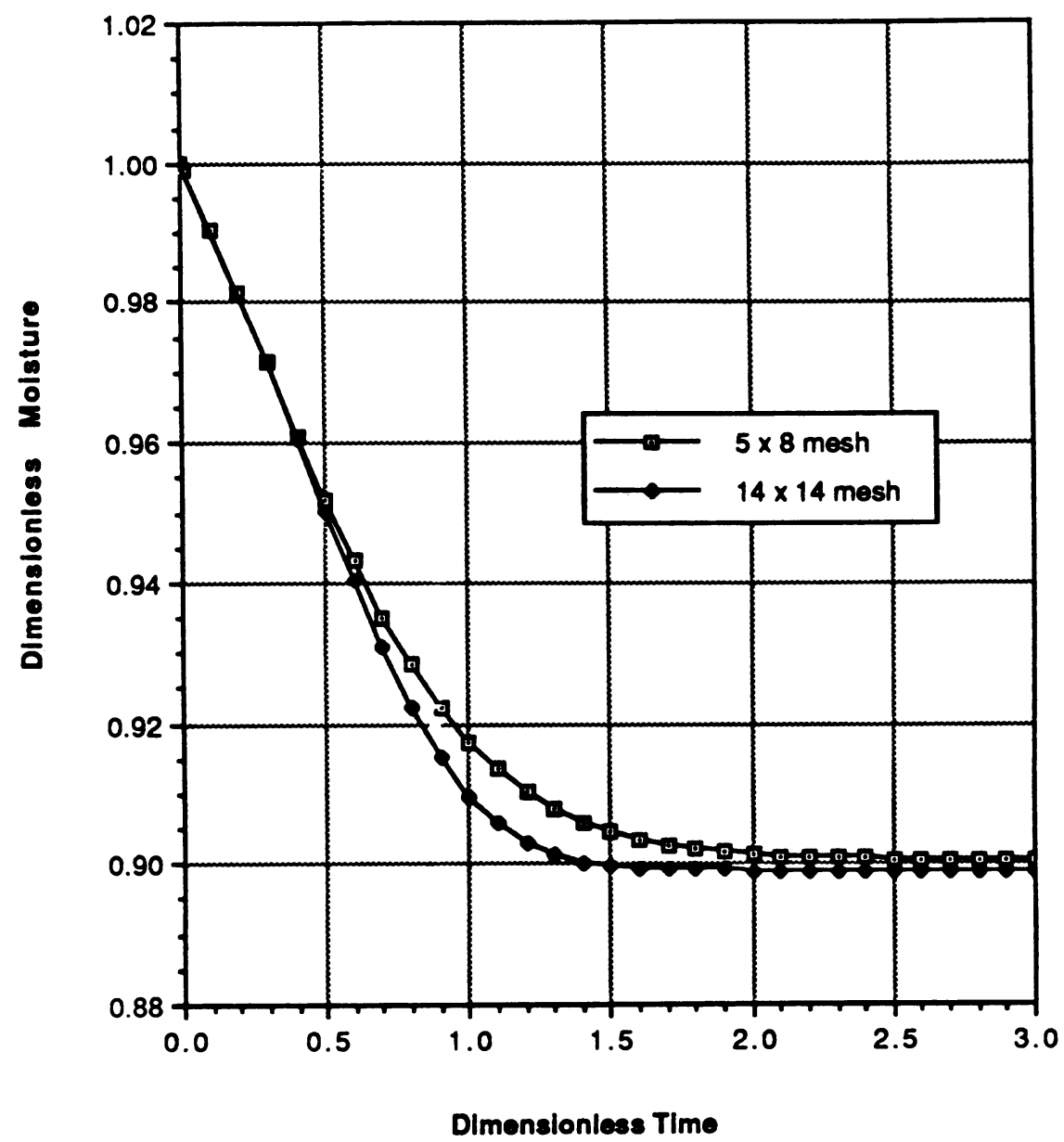

Fig. 8. Average exit rice moisture.

The simulations that led to figures 8 to 11 took 38 minutes of CPU time for the $5 \times 8$ mesh and more than 23 hours of CPU time for the $14 \times 14$ mesh.

Note that the actual steady-state for the grain is achieved faster for the $14 \mathrm{x} 14$ mesh $\left(t^{*} \sim 1.5\right)$ than for the $5 \times 8$ mesh $\left(t^{*} \sim 2\right)$. Because of the large $\beta$, we expect that increasing $N_{R}$ will cause the steady-state to be closer to $t^{*}=1$ because increasing $N_{R}$ reduces the effect of mixing in the direction of the grain flow caused by the finite $N_{R}$. 


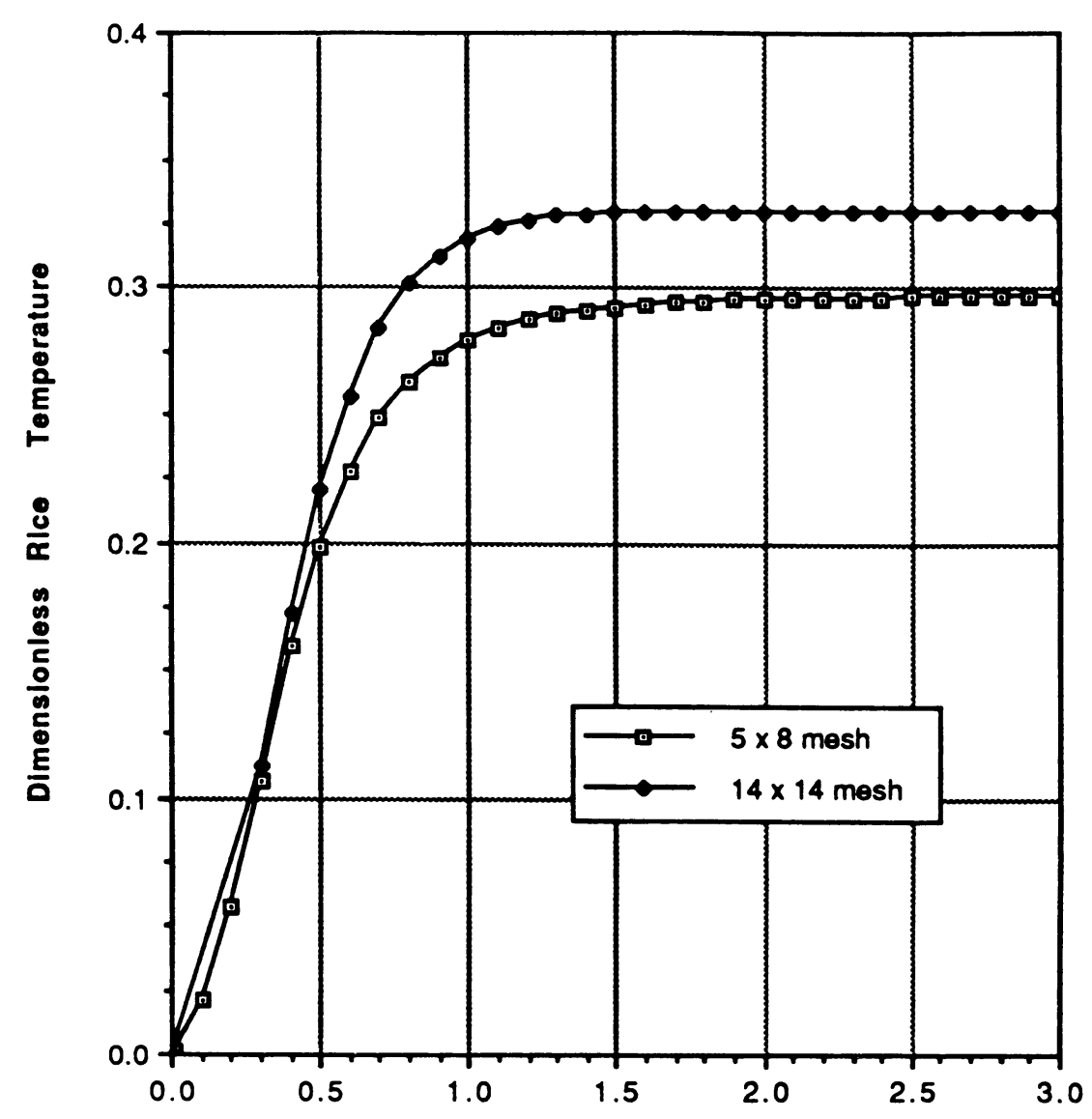

Dimenslonless Time

Fig. 9. Average exit rice temperature.

\section{Neglecting the Accumulation Terms for the Air}

In his review, Parry (1985) reported that, in grain-drying simulations, the time derivatives in the PDEs corresponding to the air properties are commonly neglected. Thus, the ODEs for $W_{j}$ and $T_{j}$, obtained by discretization of the spatial derivatives (see section 3.1), are transformed into algebraic equations. This practice is based either on experimental results or on the assumption that $\partial \mathrm{W} / \partial \mathrm{t}$ and $\partial \mathrm{T} / \partial \mathrm{t}$ are negligible. While the above assumption is justifiable, as it only concerns the steady-state (in which, 


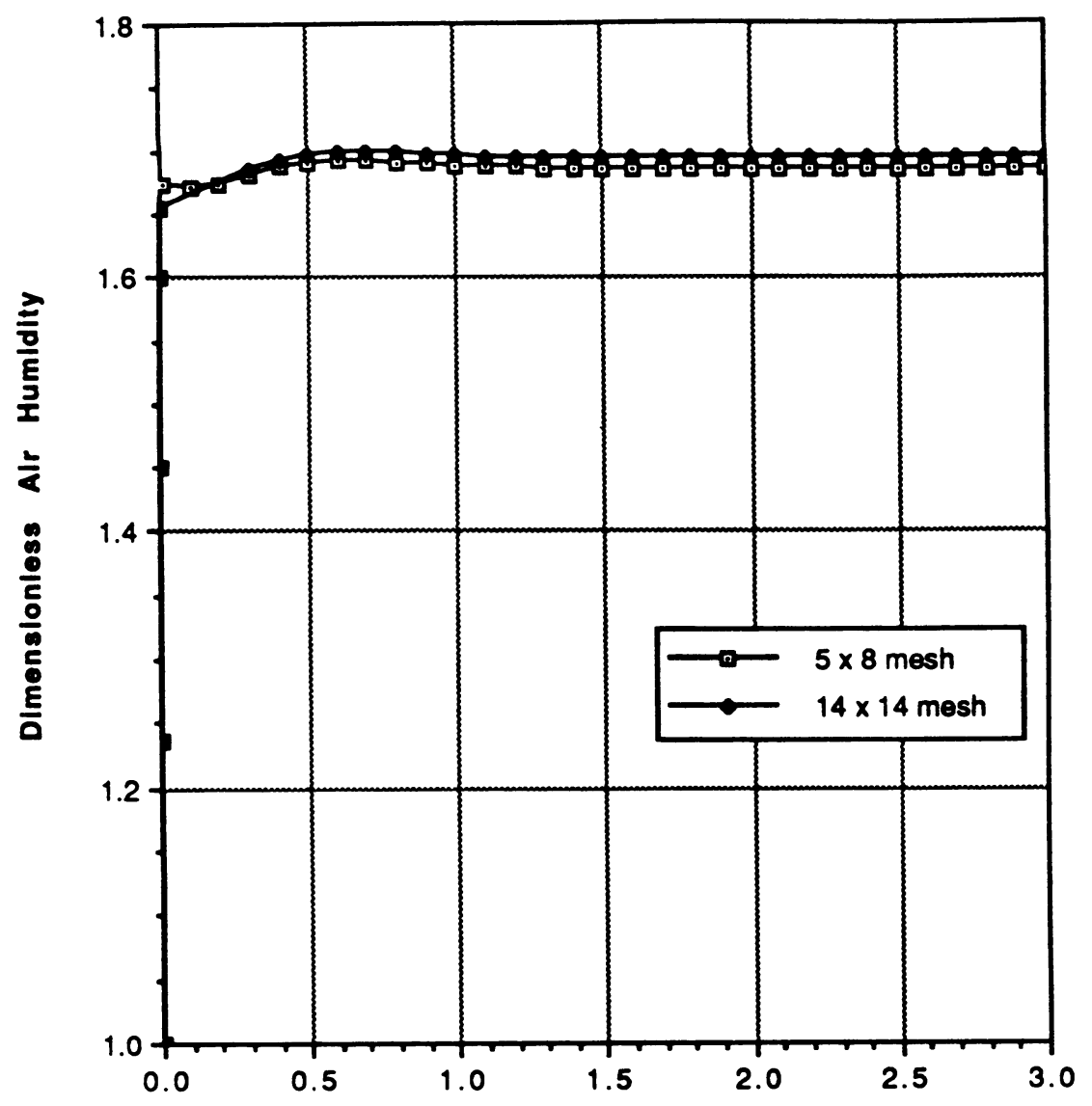

Dimensionlese Time

Fig. 10. Average exit air humidity.

by definition, the time derivatives are zero), it is physically incorrect when dealing with dynamic changes. Nevertheless, the mathematical results for the simplified model, obtained by neglecting the accumulation terms of the air, are generally close to those of the original one. The justification for assuming quasi-steady state for the air is derived from the stiffness analysis made in section 3.2, which shows that the changes in the air are typically thousands of times faster than those in the grain.

This means that when the time derivatives of the air, far from the steady-state, are very large and far from being negligible. For example, the time derivatives 


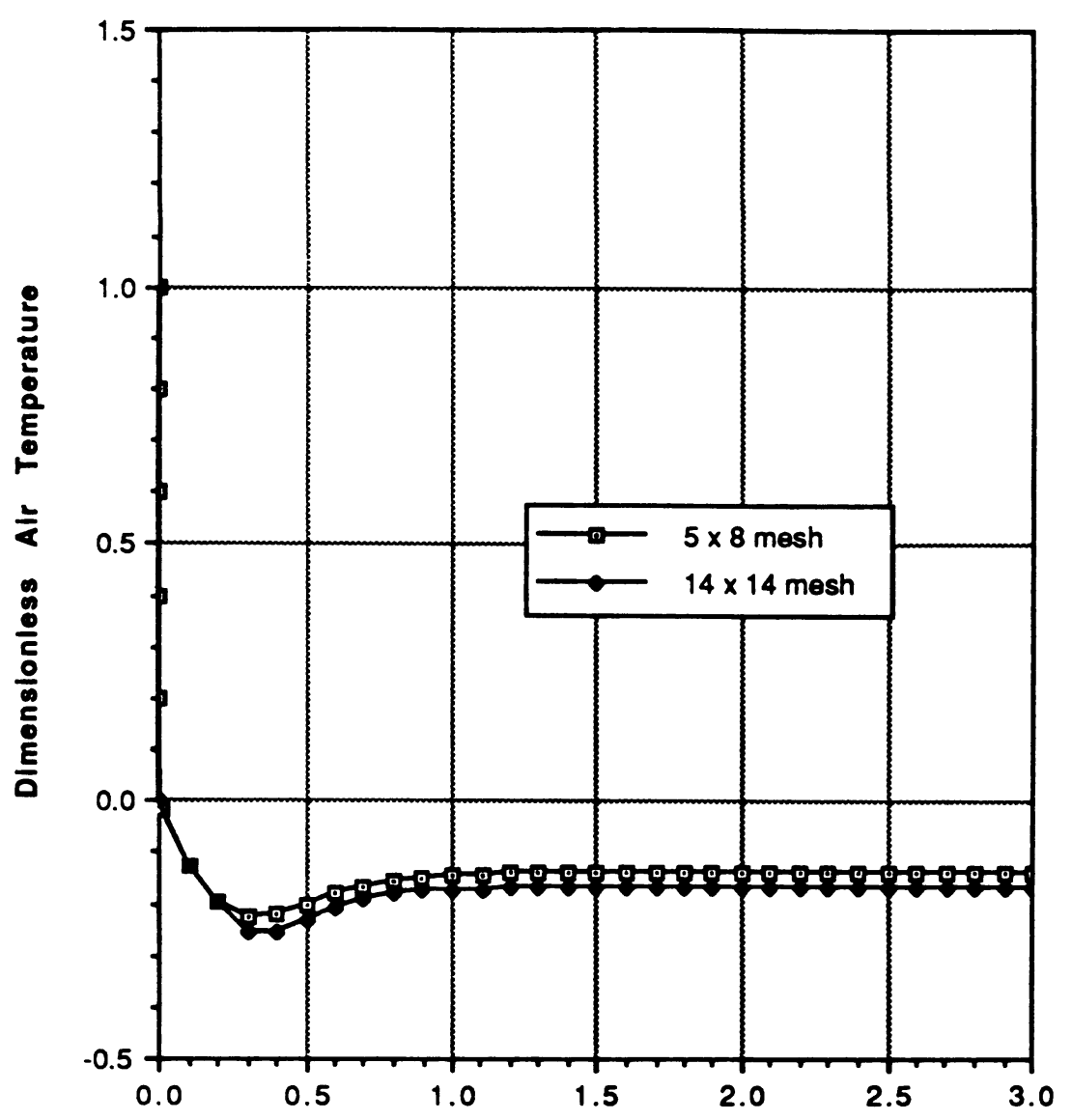

Dimenslonless Time

Fig. 11. Average exit air temperature.

$\partial \mathrm{W}^{*} / \partial \mathrm{t}^{*}$ and $\partial \mathrm{T}^{*} / \partial \mathrm{t}^{*}$ at $\mathrm{t}^{*}=0$, when beginning with the uniform distributions $\mathrm{M}^{*}\left(\mathrm{x}^{*}, \mathrm{y}^{*}, 0\right)=\mathrm{W}\left(\mathrm{x}^{*}, \mathrm{y}^{*}, 0\right)=\mathrm{T}\left(\mathrm{x}^{*}, \mathrm{y}^{*}, 0\right)=1$, and $\theta\left(\mathrm{x}^{*}, \mathrm{y}^{*}, 0\right)=0$, are found to be (from Equations [22] and [24]) $\beta \gamma$ and $\beta \psi$, respectively. In the numerical example of section 2.4, we get $\left.\frac{\partial \mathrm{W}^{*}}{\partial \mathrm{t}^{*}}\right|_{\mathrm{t}^{*}=0}=3580$ and $\left.\frac{\partial \mathrm{T}^{*}}{\partial \mathrm{t}^{*}}\right|_{\mathrm{t}^{*}=0}=63331$. 
The mathematical justification of neglecting the time derivatives of the air lies in the large coefficient $\beta$, which multiplies the right-hand sides of both Equations [22] and [24], and thus is responsible for the stiffness of the system. We may assume, for example, that $\partial \mathrm{W}^{*} / \partial \mathrm{t}^{*}$ or $\partial \mathrm{T}^{*} / \partial \mathrm{t}^{*}$ are of order of magnitude 1 , and thus are not negligible at all. In such a case, the term that $\beta$ multiplies in the corresponding equation ([22] or [24]) is of the order of magnitude $10_{-4}-10^{-3}$, and may be assumed to be zero. Neglecting the time derivatives of the air properties causes the terms multiplying $\beta$ in Equations [22] and [24] to become zero, but the justification for this is not that the time derivatives are negligible, but that $\beta$ is very large.

Neglecting the accumulation terms that correspond to the air properties generally causes step changes in the calculated air properties at $t^{*}=0$ (unless the initial conditions are such that the time derivatives for the air properties are zero). Using the $5 \times 8$ mesh in the numerical example of section 2.4 , the air humidity increases at $\mathrm{t}^{*}=0$ within zero time by $67.5 \%\left(\mathrm{~W}_{\mathrm{j}}^{*}\left(0^{+}\right)=1.675\right)$, and its temperature decreases at the same time to a value slightly higher than that of the grain temperature $\left(\mathrm{T}_{\mathrm{j}}^{*}\left(0^{+}\right)\right.$ $=6.7 \cdot 10^{-5}$ ). Thus, the calculated air properties at the outlet of the dryer quickly reach values that are quite close to those corresponding to the steady-state ones $\overline{\mathrm{W}}_{\text {out }}{ }^{*}$ $(\mathrm{s.s})=1.684$ and $\left.\overline{\mathrm{T}}_{\text {out }}{ }^{*}(\mathrm{~s} . \mathrm{s})=-0.1357\right)$. If the accumulation terms for the air are retained, it takes $7.7 \cdot 10^{-4}$ units of dimensionless time $(1.1 \mathrm{sec})$ to reach the same humidity at the outlet, and $3.2 \cdot 10^{-4}$ units of dimensionless time $(0.5 \mathrm{sec})$ to reach the same outlet temperature.

Note that the large $\beta$ causes the air properties to approach their steady-state values before the time derivatives are physically negligible. For example, at the 24 th compartment of the dryer (in the vicinity of its horizontal axis close to the air outlet), $\mathrm{dW}_{24} * / \mathrm{dt} *$ is still greater than 700 , when $\overline{\mathrm{W}}_{\text {out }}{ }^{*}$ has already passed $90 \%$ of the change towards its steady-state (reaching the value of 1.616 ).

Zeroing the time derivatives of the air properties has a negligible effect on the grain properties, although it has a considerable affect on the air properties during the first second of the simulation. The short-term effect of this simplification on the air properties together with the relatively big time constants for changes in the grain causes this effect. If we are interested mainly in the behavior of the grain and if the conditions at the dryer inlet do not fluctuate considerably (from [46b] and [46d], the frequency of the changes per unit of dimensionless time should be considerably less than $\beta$ ), we can assume, for all practical purposes, a quasi-steady state for the air.

This simplification saves a considerable amount of computer time. Without the quasi-steady state assumption for the air, the simulation corresponding to the numerical example in section 2.4 , till $\mathrm{t}^{*}=3$ with the $5 \times 8$ mesh consumed $38 \mathrm{CPU}$ minutes of VAX $11 / 785$, while the simplified model consumed only 22 CPU minutes (a saving of $42 \%$ ).

\section{4 MODEL EXTENSIONS}

The model was extended to include two optional cross-flow dryer features: an inverter and air recirculation. 


\section{Inverter}

The motivation for using an inverter in a cross-flow dryer is the reduction of grain temperature and moisture gradients across the dryer. The inverter is not intended to improve the moisture removal nor to decrease energy consumption. It may even decrease the amount of moisture removed and increase the energy consumption (Otten et al. 1980).

\section{Inverter modelling}

In the mathematical modelling of the inverter the following assumptions are made:

1. The inverter is of a zero length (it does not occupy space along the y direction).

2. The inverter does not affect the air flow.

3. The inverter changes the flow of passing grain by rotating it 180 degrees around the longitudinal axis of the dryer.

Suppose that the inverter is placed exactly on a border line separating two rows in the mesh representing the dryer (see section 3, page 20). $\mathrm{N}_{\mathrm{IVR}}$ denotes the number of the row just after which the inverter is placed, and $\langle\mathbf{j}\rangle$ denotes the grain content of the jth compartment of the mesh. The inverter operation is modelled mathematically by the relation:

$$
<\mathrm{N}_{\mathrm{IVR}} \mathrm{N}_{\mathrm{C}}+\mathrm{n}_{\mathrm{c}}-\mathrm{N}_{\mathrm{C}}>\Leftrightarrow<\mathrm{N}_{\mathrm{IVR}} \mathrm{N}_{\mathrm{C}}+1-\mathrm{n}_{\mathrm{c}}>\mathrm{n}_{\mathrm{c}}=1,2, \ldots, \mathrm{N}_{\mathrm{C}} .
$$

The inverter exchanges the grain content of the compartments listed inside the brackets of Equation [48] just before the grain passes from the $\mathrm{N}_{\mathrm{IVR}}{ }^{\text {th }}$ row to the next row. This model is slightly different from the one suggested by Otten et al. (1980). They assumed that the inverter splits the column of grain into two equal parts and that the grain in each half is completely mixed.

\section{Steady-state analysis}

The numerical study of the inverter uses a dryer with data identical to those listed in table 1 . The inverter is placed in the middle of the dryer $\left(y^{*}=0.5\right)$. The numerical solution uses a mesh of $6 \times 8$ (a $5 \times 8$ mesh does not represent an inverter at $\mathrm{y}^{*}=0.5$, whereas a $6 \times 8$ mesh with $\mathrm{N}_{\mathrm{IVR}}=3$ does). Table 4 shows the steady-state distributions of the four dimensionless variables $\left(\mathrm{M}^{*}, \theta^{*}, \mathrm{~W}^{*}, \mathrm{~T}^{*}\right)$, the dimensionless drying rate, $\mathrm{R}^{*}$, and the relative humidity, $\mathrm{rh}$, in the mesh compartments.

The average values of the grain and air properties at the outlets in steady-state are given below with the values obtained for a $14 \times 14$ mesh in parentheses:

$$
\begin{array}{ll}
\overline{\mathrm{M}}_{\text {out }}{ }^{*}(\mathrm{~s} . \mathrm{s})=0.9028(0.9022) & \bar{\theta}_{\text {out }}{ }^{*}(\mathrm{~s} . \mathrm{s})=0.2109(0.2270) \\
\overline{\mathrm{W}}_{\text {out }}{ }^{*}(\mathrm{~s} . \mathrm{s})=1.6686(1.6728) & \overline{\mathrm{T}}_{\text {out }}{ }^{*}(\mathrm{~s} . \mathrm{s})=-0.0655(-0.0805) .
\end{array}
$$

Comparison between the steady-state values at the outlets for the $6 \times 8$ and the $14 \times 14$ meshes indicates that, for most practical needs, the $6 \times 8$ division is satisfactory.

Table 5 shows how the location of the inverter along the y axis affects the steady-state average properties of the grain and the air at the outlets. Simulations were made for $\mathrm{N}_{\text {IVR }}=0,2,3$, and 4 , corresponding to $\mathrm{y}^{*}=0$ (no inverter), $0.333,0.5$, and 0.667 , respectively. Table 5 shows that the inverter does not considerably influence the mass 


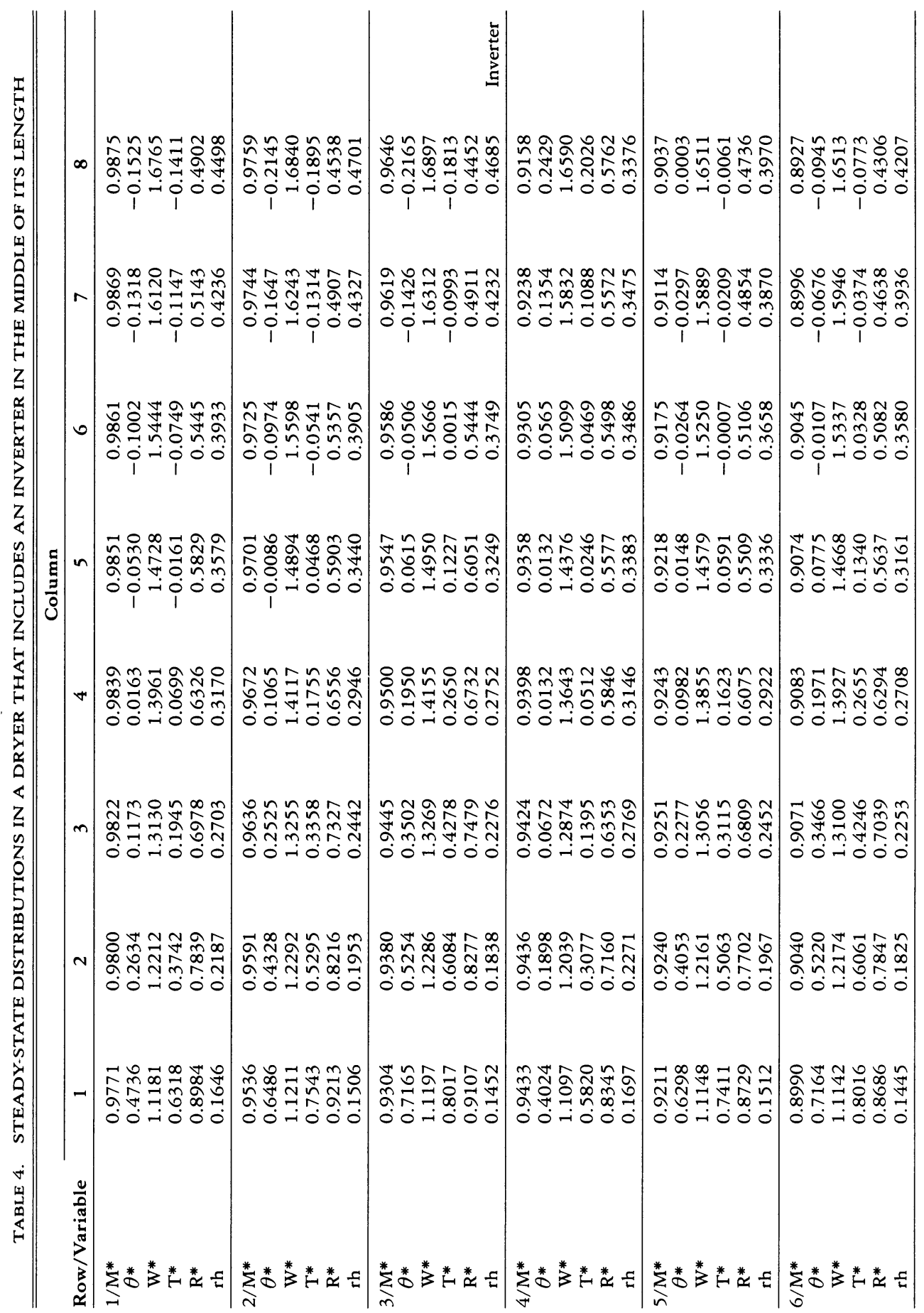


transfer in the dryer. $\overline{\mathrm{M}}_{\text {out }}{ }^{*}$ (s.s) and $\overline{\mathrm{W}}_{\text {out }}{ }^{*}$ (s.s) do not change much with the location of the inverter. Not using an inverter yields a slightly dryer grain. The inverter can decrease the average grain temperature at the outlet about $1.5^{\circ} \mathrm{C}$ (when placed in $\mathrm{y}^{*}=0.667$ ), and may increase the average air temperature at the outlet about $1^{\circ} \mathrm{C}$ (when placed in $y^{*}=0.5$ to 0.6 ). Figures 12 and 13 show the effect of the inverter as it reduces the existing gradients in the dryer. If we compare figure 2 with figure $12 \mathrm{a}$, we see that the exit moisture distribution in figure 2 is much narrower, giving rise to a much more homogenous product. However, the temperature distribution (figs. 3 and 13a) is not affected as much, displaying a slight reduction in the exit temperature distribution.

\section{Dynamic simulation}

A rice-drying experiment was done by personnel from the Agricultural Engineering Department of UC Davis using a commercial dryer, whose data are given in table 1, but with two changes:

1. An inverter was placed in its center $\left(y^{*}=0.5\right)$.

2. The inlet moisture, instead of being constant with a value of 0.228 , changed in time around an average value of about 0.228 .

Figure 14 shows the points corresponding to the experimental inlet and outlet moistures of the grain and a curve for the outlet moisture, obtained by a numerical simulation. As no continuous data for the inlet moisture are available, we assume that the curve for the inlet moisture can be approximated by linear interpolation between the corresponding points. The simulation assumes that the dryer begins its operation from the steady-state, corresponding to the initial inlet moisture. This is the reason for the zero slope of the simulation curve at $t=0$. As the first measurement for the outlet moisture was taken more than an hour after the beginning of the experiment (designated by $t=0$ ), and the residence time for the grain is about 25 minutes, the initial conditions assumed for the dryer have a very small effect on the fit of the simulation curve to the experimental points.

Comparison between the simulation curve and the experimental points for the outlet moisture shows a good agreement except for the three measurements taken after 60 , 190, and 525 minutes from the beginning of the experiment. The large deviations for these three points are most probably due to the large time intervals between two successive data points of the inlet moisture (generally of about 1 hour, while the residence time of the grain is only 25 minutes). Thus, the linear interpolation used to

TABLE 5. THE INFLUENCE OF THE INVERTER LOCATION ON THE DRYER OUTPUTS AT STEADY-STATE

\begin{tabular}{lcccc}
\hline \hline $\mathbf{y}^{*}$ & $\overline{\mathbf{M}}_{\text {out }}{ }^{*}$ (s.s) & $\bar{\theta}_{\text {out }}{ }^{*}$ (s.s) & $\overline{\mathbf{W}}_{\text {out }}{ }^{*}$ (s.s) & $\overline{\mathbf{T}}_{\text {out }}{ }^{*}$ (s.s) \\
\hline 0 (no inverter) & 0.9005 & 0.2996 & 1.6849 & -0.1387 \\
0.333 & 0.9031 & 0.2408 & 1.6669 & -0.0800 \\
0.5 & 0.9028 & 0.2109 & 1.6686 & -0.0655 \\
0.667 & 0.9021 & 0.1935 & 1.6735 & -0.0626 \\
\hline
\end{tabular}




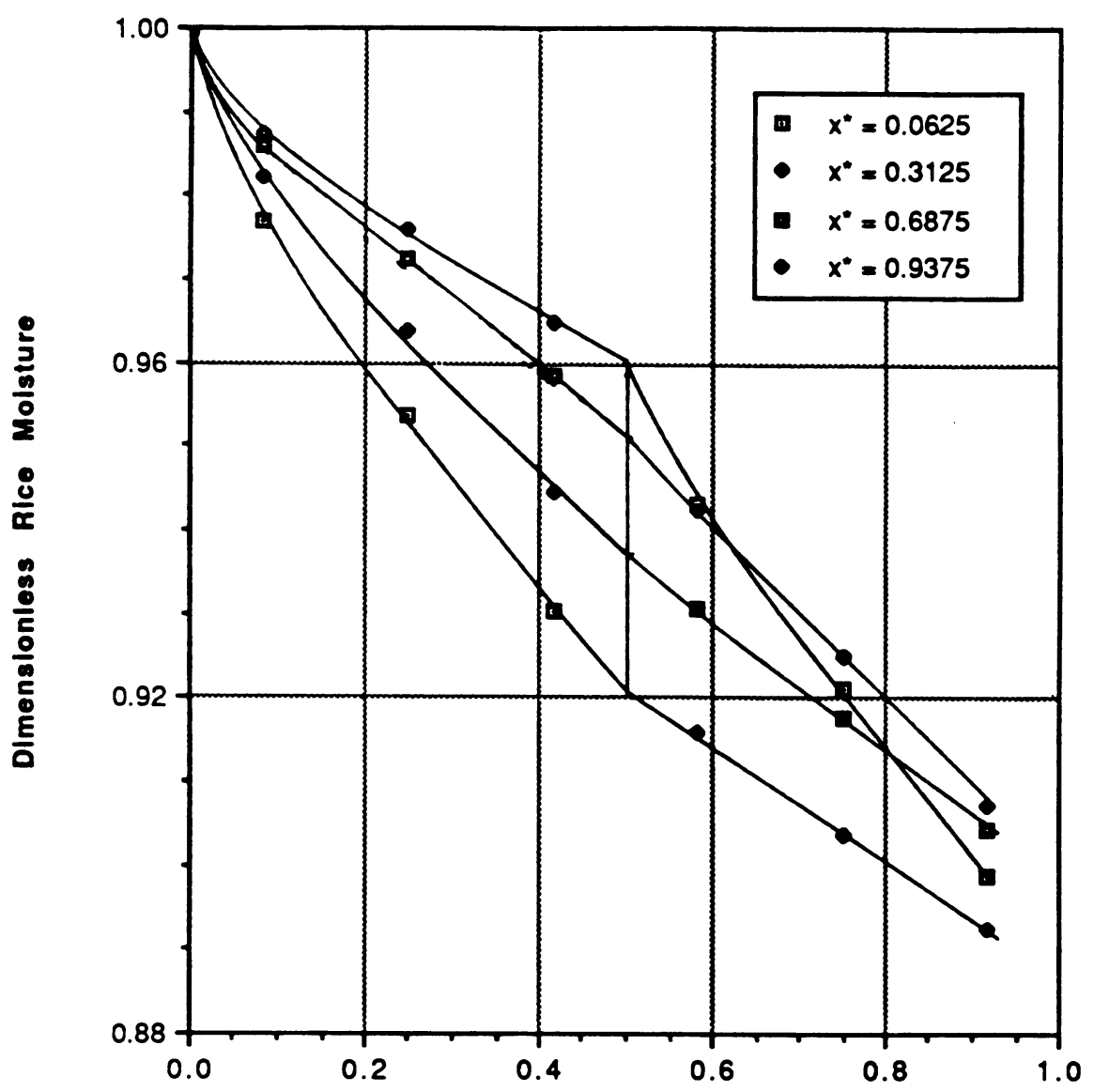

Dimenslonless Longth

Fig. 12a. Rice moisture profiles with inverter.

evaluate the inlet moisture in the intervals between the data points may yield a poor estimate in periods when the inlet moisture changes abruptly or oscillates with large amplitudes. Examination of figure 14 for one residence time preceding the three deviating measurements reveals that the approximated function for the inlet moisture there has relatively large slopes. Therefore, the inlet moisture in these regions, which affects the deviating measurements, may be expected to be poorly represented by the linear interpolation estimate. 


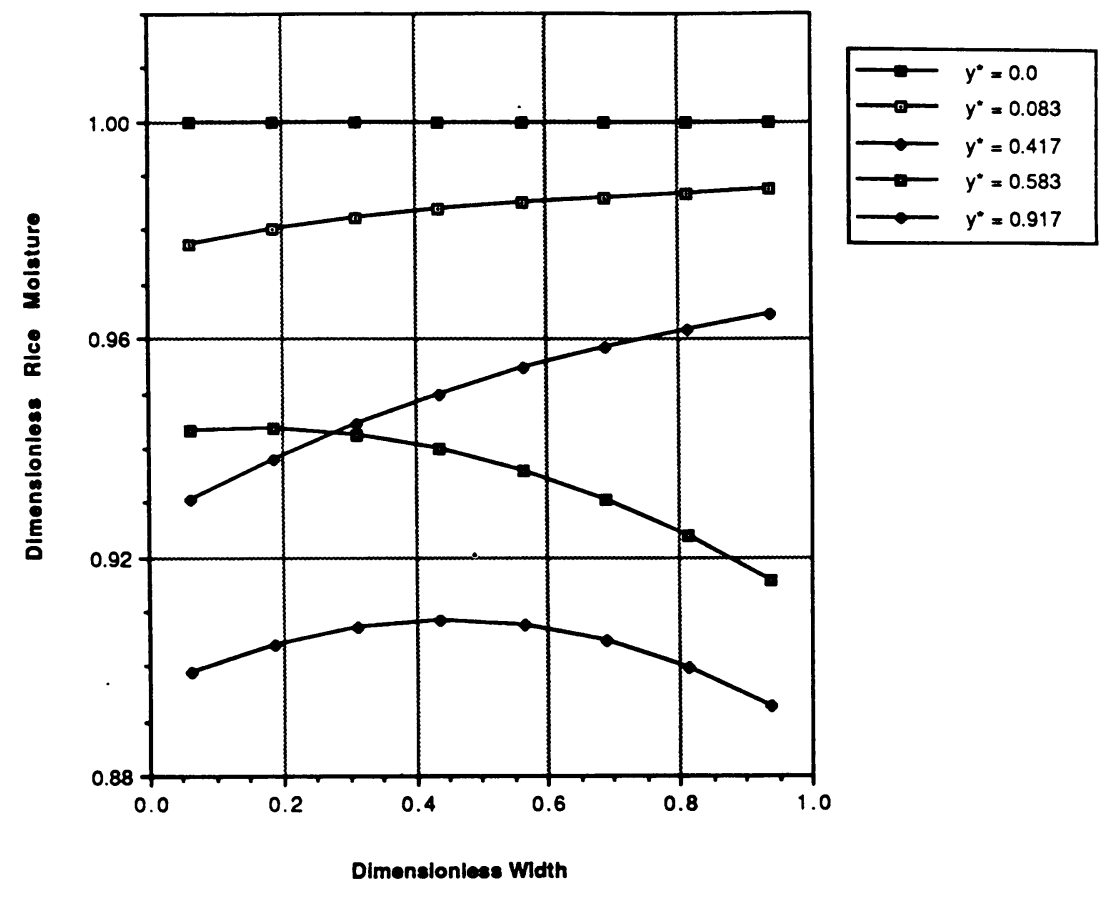

Fig. 12b. Moisture profiles before and after inverter.

\section{Air Recirculation}

The model is extended to handle recirculation of the drying air from the lower portion of the dryer. The motivation for air recirculation is to save the energy required to heat the drying air.

\section{Air recirculation modelling}

The recirculating air, taken from the portion of the dryer over the range $y_{r}<y \leq L$, is assumed to be well mixed with the ambient make-up air. Mass balance on the water vapor gives (Rumsey, 1986)

$$
W_{\text {in }}(t)=\frac{y_{r}}{L} W_{a m b}(t)+\frac{1}{L} \int_{y_{r}}^{L} W(b, y, t) d y .
$$

Suppose that $y=y_{r}$ is a border line separating two rows in the mesh representing the dryer (see section 3.1), and denotes by $\mathrm{N}_{\mathrm{RC}}$ the number of the row that belongs to the upper portion of the dryer. Equation [49] in terms of the mesh compartments becomes 


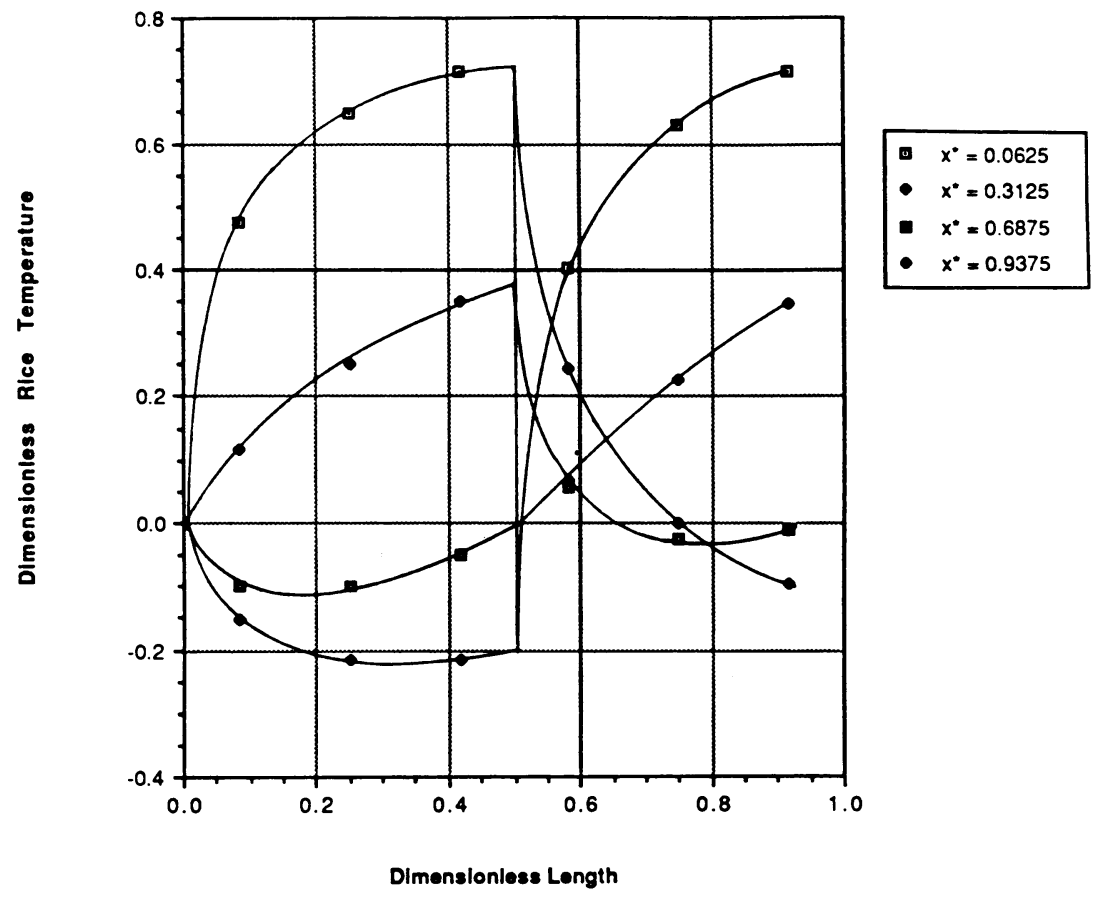

Fig. 13a. Steady-state rice temperature profiles with inverter.

$$
W_{\text {in }}=\left(W_{a m b} \cdot N_{R C}+\sum_{j=1}^{N_{R}-N_{R C}} W_{\left(N_{R C}+j\right) N_{C}}\right) / N_{R} .
$$

\section{Steady-state analysis}

The same commercial rice dryer used in the previous experiment for the inverter (see Dynamic simulation, page 32) serves to examine the air recirculation feature. In addition to the inverter at $y^{*}=0.5$, one-third of the air is assumed to be recirculated $\left(y_{r}{ }^{*}=0.667\right)$. The operating conditions are chosen to match the initial ones in the experiment described in the next section. The operating conditions for the dryer are summarized in table 6 together with the calculated characteristic rate of drying, inlet and make-up air relative humidities, and the six dimensionless groups characterizing the dryer. (In all the above calculations $\mathrm{W}_{\mathrm{amb}}$ is substituted for $\mathrm{W}_{\text {in }}[0]$.) The air and moving bed parameters not directly concerning the inlet conditions ( $\mathrm{L}, \mathrm{b}, \epsilon, \rho \mathrm{a}, \rho, \mathrm{C}_{\mathrm{pa}}$, $\mathrm{C}_{\mathrm{pg}}, \mathrm{H}_{\mathrm{w}}-\mathrm{h}_{\mathrm{w}}$ ) are all assumed to have the same values listed in table 1 . The steadystate average values for the grain and air properties at the dryer outlets, as obtained by solution of the mathematical model, are 


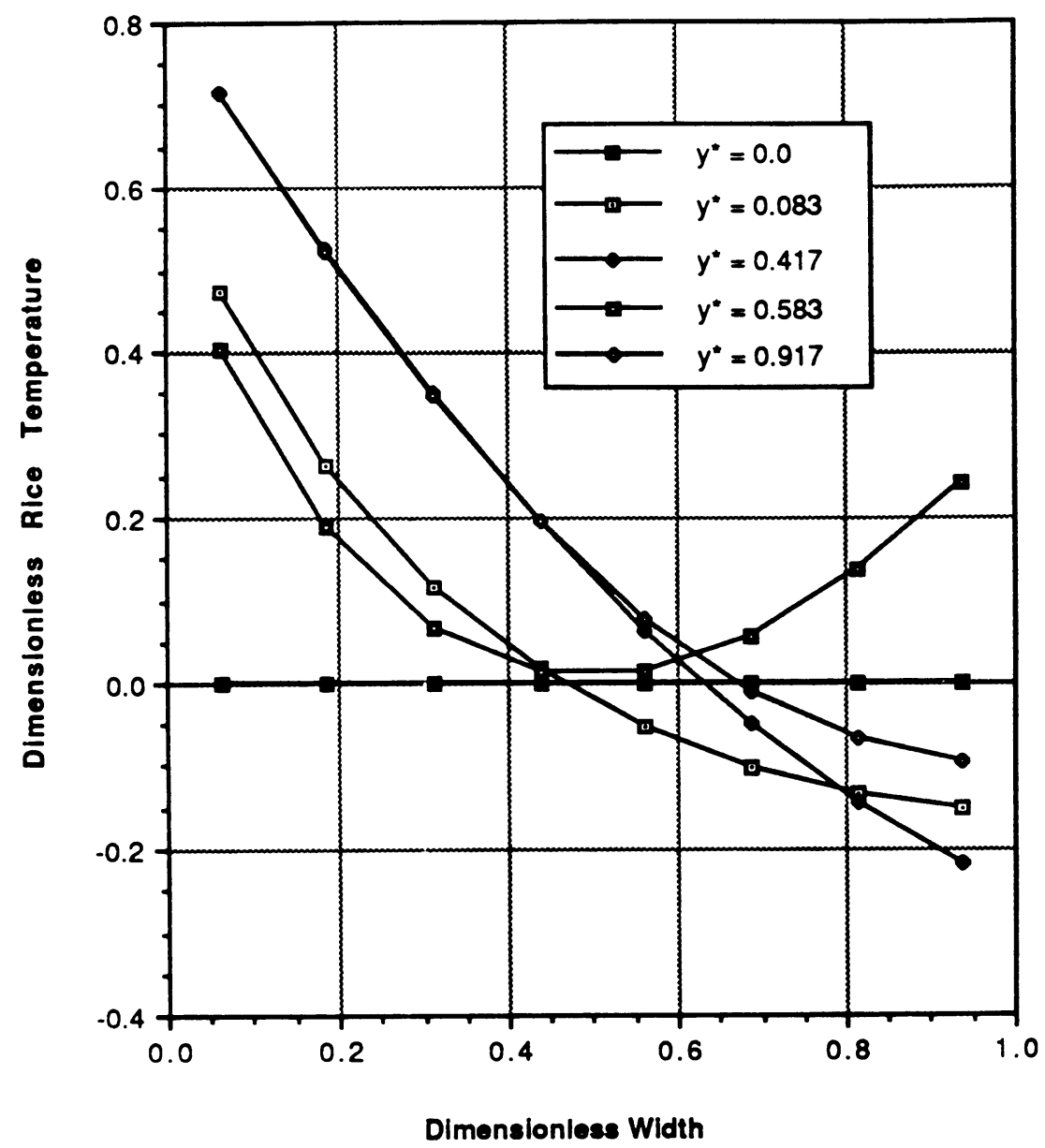

Fig. 13b. Temperature profiles before and after inverter.

$$
\begin{aligned}
& \overline{\mathrm{M}}_{\text {out }}{ }^{*}(\mathrm{~s} . \mathrm{s})=0.9140 \\
& \overline{\mathrm{W}}_{\text {out }}{ }^{*}(\mathrm{~s} . \mathrm{s})=1.9489
\end{aligned}
$$

$$
\begin{aligned}
& \bar{\theta}_{\text {out }}{ }^{*}(\mathrm{~s} . \mathrm{s})=0.5437 \\
& \overline{\mathrm{T}}_{\text {out }}{ }^{*}(\mathrm{s.s})=0.2583
\end{aligned}
$$

Table 7 shows the steady-state distributions of $\mathrm{M}^{*}, \theta^{*}, \mathrm{~W}^{*}, \mathrm{~T}^{*}, \mathrm{R}^{*}$, and $\mathrm{rh}$ in the $6 \times 8$ mesh compartments of the dryer. The inverter is placed between rows 3 and 4 , while the air leaving rows 5 and 6 is recirculated. Table 7 shows that the recirculated air has a dimensionless temperature, $\mathrm{T}^{*}$, of about 0.387 , which means it is $9.2^{\circ} \mathrm{C}$ higher than the inlet temperature of the grain. This means that if the outlet grain 


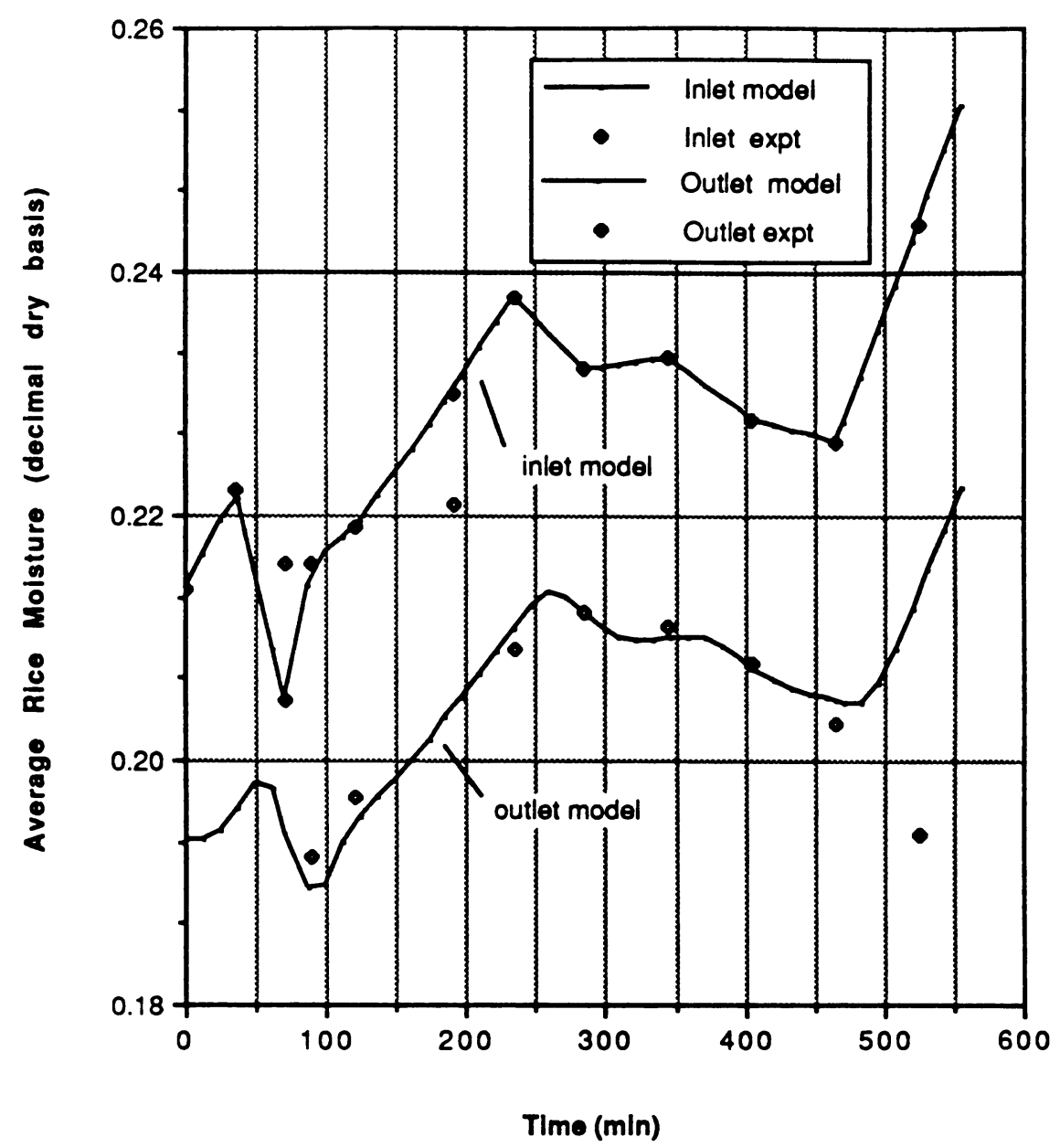

Fig. 14. Measured and predicted average rice moistures.

moisture does not increase considerably as a result of the air recirculation, a significant energy saving is obtained by this feature. Moveover, table 7 suggests that an additional energy saving is expected by recirculating the air leaving row 4 as well ( $T^{*}$ for this air is 0.517 , which means $12.4^{\circ} \mathrm{C}$ higher than $\theta_{\text {in }}$ ) and maybe by recirculating even the air leaving row $3\left(\mathrm{~T}^{*}=0.169\right.$, which means $4^{\circ} \mathrm{C}$ higher than $\left.\theta_{\text {in }}\right)$.

Table 8 summarizes the dependence of the operating conditions at steady-state on the air fraction recirculated, $1-\mathrm{y}_{\mathrm{r}}{ }^{*}$. The dryer examined has the same data given in table 6 except for $\mathrm{y}_{\mathrm{r}}{ }^{*}$, which changes along the table, and $\mathrm{rh}_{\mathrm{in}}$, which depends on $\mathrm{y}_{\mathrm{r}}{ }^{*}$. In 
TABLE 6. OPERATING CONDITIONS AND CALCULATED PARAMETERS IN THE SIMULATION FOR A DRYER WITH AN INVERTER AND AIR RECIRCULATION

\begin{tabular}{|c|c|c|}
\hline \multicolumn{2}{|c|}{ Inverter in $y^{*}=0.5$} & Recycle $=0.333\left(y_{\mathrm{r}} *=0.667\right)$ \\
\hline $\mathbf{M}_{\text {in }}$ & 0.196 & $\mathrm{~T}_{\mathrm{in}}=51.67$ \\
\hline $\mathrm{W}_{\mathrm{amb}}$ & 0.0073 & $\mathrm{G}_{\mathrm{p}}=8.588$ \\
\hline$\theta_{\text {in }}$ & 27.78 & $\mathrm{G}_{\mathrm{a}}=0.4211$ \\
\hline $\mathrm{R}_{\mathrm{c}}$ & 0.0679 & $\gamma=1.030$ \\
\hline $\mathrm{rh}_{\mathrm{amb}}$ & 0.0877 & $\delta=33.444$ \\
\hline $\mathrm{rh}_{\mathrm{in}}$ & 0.1162 & $\phi=9.116$ \\
\hline$\alpha$ & $=0.143$ & $=18.683$ \\
\hline$\beta$ & $=3447.3$ & \\
\hline
\end{tabular}

addition to the average grain and air properties at the outlets, the table gives the inlet relative humidity of the air, $\mathrm{rh}_{\mathrm{in}}$, and the average dimensionless temperature of the recirculated air leaving the dryer, $\mathrm{T}_{\mathrm{r}}{ }^{*}$. The multiplication $\left(1-\mathrm{y}_{\mathrm{r}}{ }^{*}\right) \mathrm{T}_{\mathrm{r}}{ }^{*}$ expresses the potential for saving energy by air recirculation. The higher $\left(1-y_{r}{ }^{*}\right) T_{r}{ }^{*}$, the greater the energy saving to be expected. The compromise between the two contradicting trends of increasing $\left(1-\mathrm{y}_{\mathrm{r}}{ }^{*}\right) \mathrm{T}_{\mathrm{r}}{ }^{*}$ and lowering $\overline{\mathrm{M}}_{\text {out }}{ }^{*}$ determines the fraction of air to be recirculated.

Figure 15 shows the variation of $\left(1-\mathrm{y}_{\mathrm{r}}{ }^{*}\right) \mathrm{T}_{\mathrm{r}}{ }^{*}$ and $\bar{M}_{\text {out }}{ }^{*}$ (s.s) with the fraction recirculated, $1-\mathrm{y}_{\mathrm{r}}{ }^{*}$. From these curves, the optimum recirculation lies near $1-\mathrm{y}_{\mathrm{r}}{ }^{*}=0.5$ (corresponding to the inflection point in the curve for $\left(1-\mathrm{y}_{\mathrm{r}}{ }^{*}\right) \mathrm{T}_{\mathrm{r}}{ }^{*}$ ). With half of the air recirculated, considerable energy is saved, whereas the outlet moisture of the grain does not increase much in relation to a dryer without recirculation $\left(\bar{M}_{\text {out }}=0.180\right.$ vs. $\bar{M}_{\text {out }}=0.178$, while $\left.M_{\text {in }}=0.196\right)$. The reason for this relatively small difference in the outlet moistures is the low sensitivity of the drying rate to changes in the inlet air humidity when the air humidity is low. Changing the inlet relative humidity, $\mathrm{rh}_{\mathrm{in}}$, in the above dryer from $0.0877\left(1-\mathrm{y}_{\mathrm{r}}{ }^{*}=0\right)$ to $0.1415\left(1-\mathrm{y}_{\mathrm{r}}{ }^{*}=0.5\right)$ changes the average rate of drying $\overline{\mathrm{R}}_{\mathrm{s.s}}{ }_{\mathrm{s}}$ from 0.641 to 0.568 . Thus, an increase of about $61 \%$ in the inlet relative humidity causes a decrease of only about $11 \%$ in the drying rate.

Large amounts of air recirculation $\left(1-\mathrm{y}_{\mathrm{r}}{ }^{*}=0.833\right.$ or 1$)$ produce negative rates of drying in a region around the corner of the dryer common to both the grain inlet and the air outlet $\left(\mathrm{x}^{*}=1, \mathrm{y}^{*}=0\right)$. The higher the recirculation ratio, the larger that region becomes. For the limiting case of a complete recirculation $\left(1-\mathrm{y}_{\mathrm{r}}{ }^{*}=1\right)$, relative humidities of $100 \%$ exist in a part of the above region. Chung's equation for the equilibrium moisture content (see section 2.2.1) is not applicable in this case, yielding an infinite $M_{e}$, which results in an infinite negative rate of drying. Therefore, a modification to the model is required. The absolute and the relative humidities were limited by their saturation values, and the rate of drying was limited by $-R_{c}$ (that is, $\operatorname{MIN}\left\{R^{*}\right\}=-1$ ).

\section{Dynamic simulation}

The data given in table 6 describe (with small variations) a dryer used by personnel 


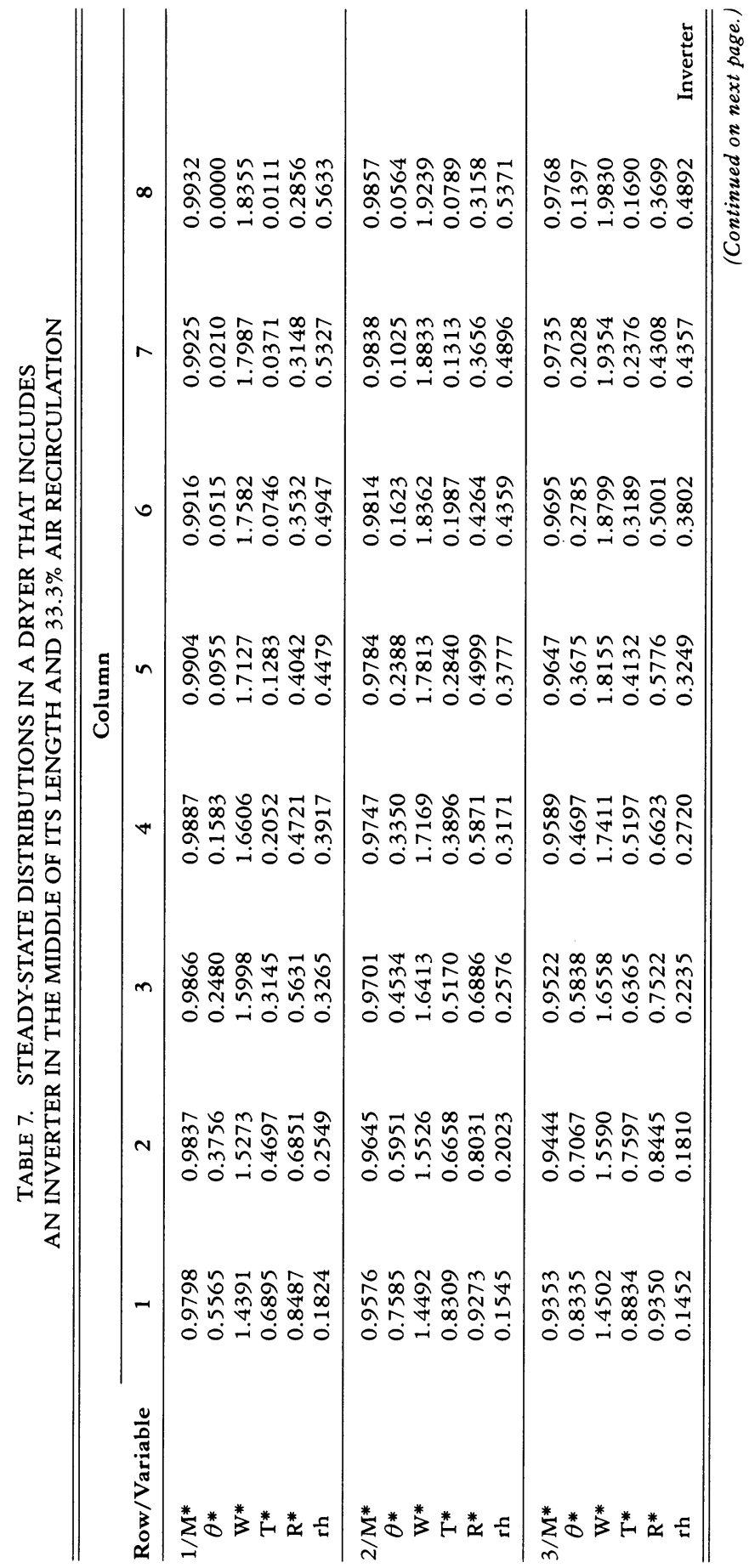




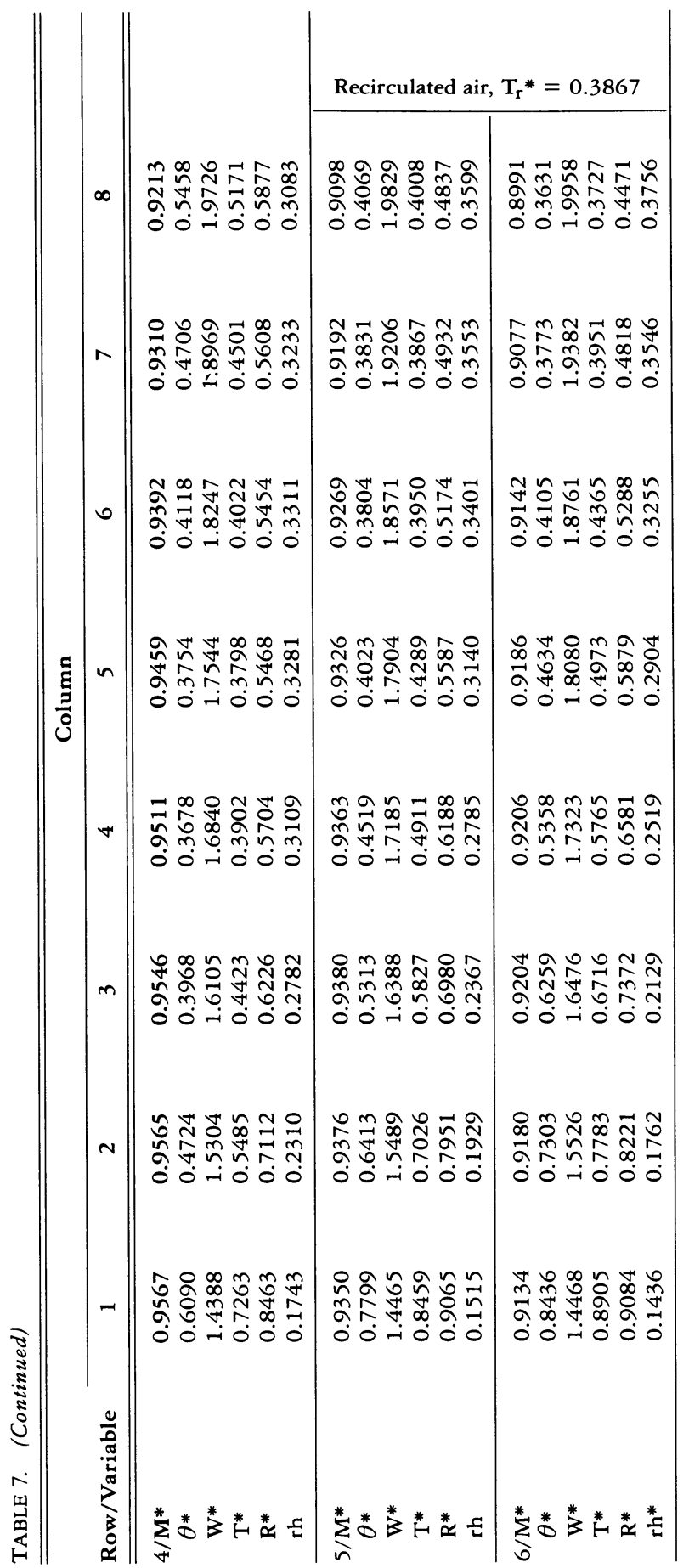


TABLE 8. DEPENDENCE OF THE STEADY-STATE ON THE AIR FRACTION RECIRCULATED

\begin{tabular}{|c|c|c|c|c|c|c|c|}
\hline $1-y_{r} *$ & $\mathbf{r h}_{\text {in }}$ & $\mathbf{T}_{\mathrm{r}} *$ & $\overline{\mathbf{M}}_{\text {out }}{ }^{*}(\mathrm{~s} . \mathrm{s})$ & $\bar{\theta}_{\text {out }}^{*}($ s.s $)$ & $\overline{\mathbf{W}}_{\text {out }}{ }^{*}(\mathrm{s.s})$ & $\overline{\mathrm{T}}_{\text {out }}{ }^{*}(\mathrm{~s} . \mathrm{s})$ & $\left(1-y_{r}^{*}\right) T_{r} *$ \\
\hline 0 & 0.0877 & 0.2392 & 0.9083 & 0.5260 & 1.6602 & 0.2392 & 0 \\
\hline 0.167 & 0.0995 & 0.3583 & 0.9107 & 0.5336 & 1.7797 & 0.2473 & 0.06 \\
\hline 0.333 & 0.1162 & 0.3867 & 0.9140 & 0.5437 & 1.9489 & 0.2583 & 0.129 \\
\hline 0.5 & 0.1415 & 0.4482 & 0.9188 & 0.5585 & 2.2097 & 0.2745 & 0.224 \\
\hline 0.667 & 0.1859 & 0.4132 & 0.9268 & 0.5827 & 2.6749 & 0.3018 & 0.275 \\
\hline 0.833 & 0.2792 & 0.4158 & 0.9434 & 0.6297 & 3.6750 & 0.3601 & 0.347 \\
\hline 1 & 0.5324 & 0.5725 & 1.0000 & 0.7652 & 6.4561 & 0.5725 & 0.573 \\
\hline
\end{tabular}

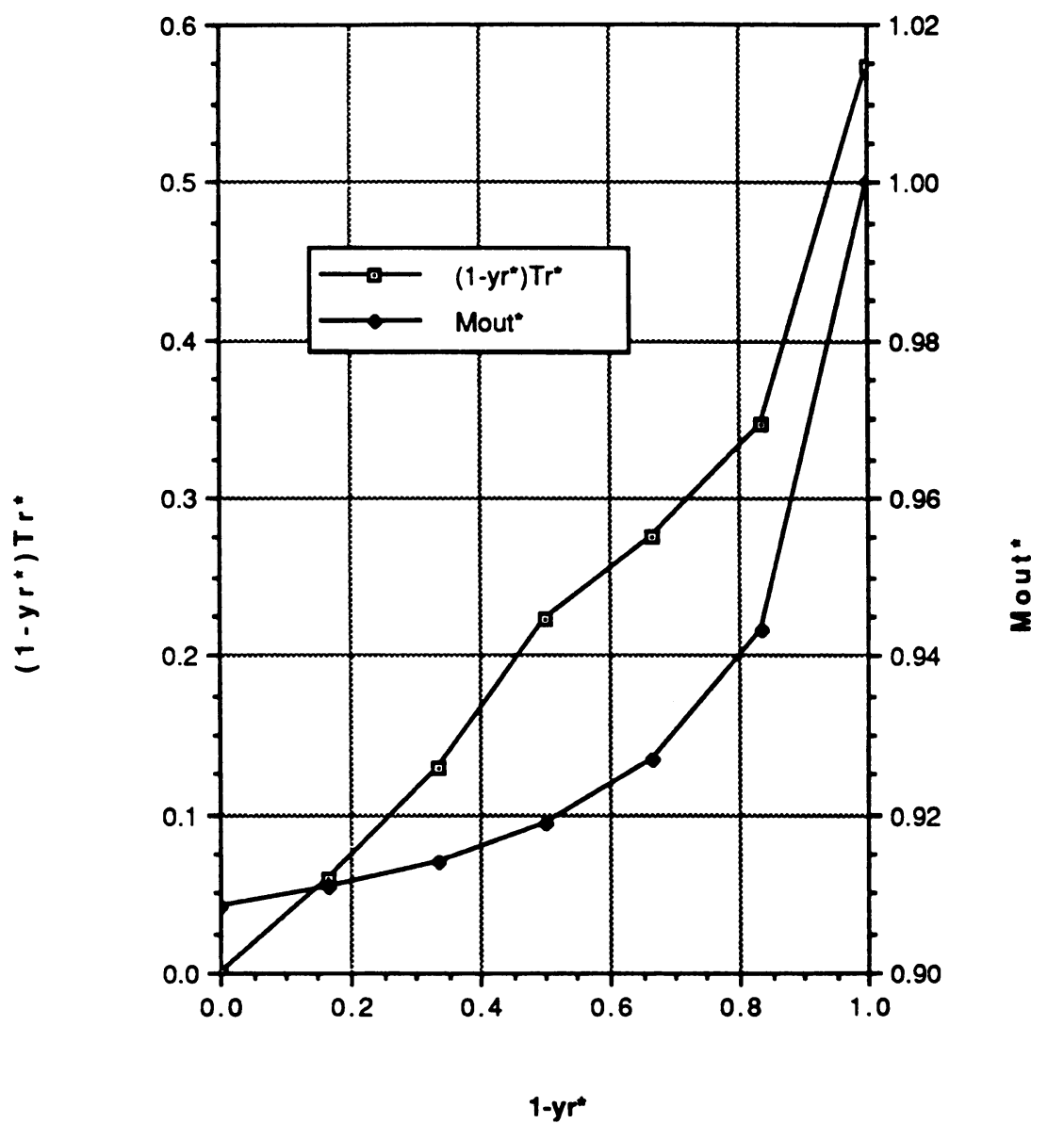

Fig. 15. Effects of air recirculation on energy saving and exit moisture. 
from the Agricultural Engineering Department at UC Davis in an experiment for testing the response of a cross-flow rice dryer, with an inverter and air recirculation, to changes in the amount of air recirculation. The experiment conditions differ from the data given in table 6 in two specifications:

1. The air recirculation was $38 \%$ and not $33.3 \%$.

2. The inlet moisture, instead of being constant with a value of 0.196 , changed in time with an initial value of 0.196 .

As in figure 14, figure 16 shows the points corresponding to the experimental inlet

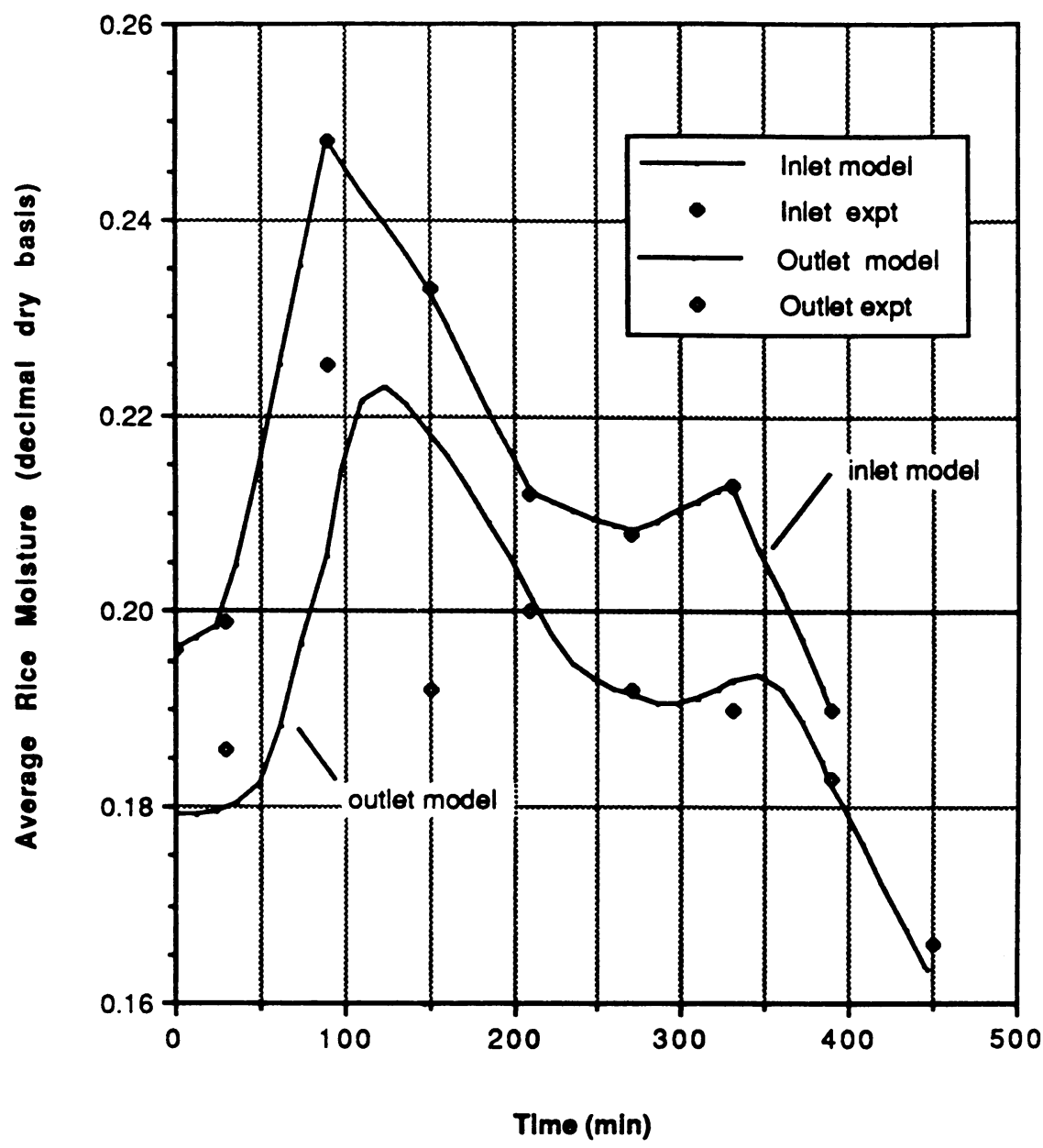

Fig. 16. Measured and predicted average rice moistures. 
and outlet moistures of the grain and a curve for the outlet moisture obtained by solution of the model. Simulations are carried out for air recirculation of $33.3 \%$ $\left(\mathrm{N}_{\mathrm{RC}}=4\right)$ rather than $38 \%$ (a mesh consisting of six rows cannot represent a recirculation of $38 \%$ ). However, the influence of such a difference on the simulation is negligible (see table 8 for the small differences in the outlet moistures, corresponding to $33.3 \%$ and $50 \%$ ). The same limitations and assumptions for figure 14 apply to figure 16. As in figure 14, the comparison between the simulation curve and the experimental points for the outlet moisture generally shows a good fit. Both curves oscillate in the same range and basically have similar shapes. Large deviations of the model from the experimental measurements are observed for times leading by about one residence time of the grain (about 25 minutes) regions of relatively large slopes in the approximated function for the inlet moisture. In such a region, for times between 30 and 150 minutes, it seems that the experimental outlet moisture follows the approximated inlet moisture without any lag. This indicates a poor approximation for the inlet moisture in this region. Unlike the experimental measurements, the simulation curve for the outlet moisture always follows the approximated inlet moisture curve with a lag of about one residence time. The reason for the smooth simulation curve in contrast to the discontinuous slope characterizing the approximated inlet moisture curve, is that the dryer is represented by a finite number of mixed compartments, which dampens the response.

\section{CONCLUSIONS}

A general, unsteady-state model of cross-flow grain drying is developed, which handles optional features such as an inverter and air recirculation. Writing the PDEs in a dimensionless form shows that the process is governed basically by only six dimensionless groups. Investigation of this stiff system of PDEs shows that for most practical needs one may assume a quasi-steady state for the air, zeroing the time derivatives for its humidity and temperature.

The model is solved numerically by the Method of Lines using ACSL. A mesh of $5 \times 8$ seems to be quite satisfactory. Application of the model to rice drying shows good correlation with dynamic experiments in which the inlet moisture of the rice changes in time.

Using an inverter seems to help reduce moisture gradients across the dryer with little effect on the average outlet moisture. Applying air recirculation saves energy, but increases the outlet moisture of the grain. For a dryer with an inverter in the center, the optimal recirculation ratio is around 0.5 . 


\section{NOMENCLATURE}

A, coefficient in Wagner's equation, Eq. [11]

$\mathrm{b}$, dryer width, $\mathrm{m}$

B, coefficient in Wagner's equation, Eq. [11]

C, coefficient in Wagner's equation, Eq. [11]

$\mathrm{C}_{\mathrm{pa}}$, specific heat of humid air, $\mathrm{J} / \mathrm{kg}$ dry air $-{ }^{\circ} \mathrm{C}$

$\mathrm{C}_{\mathrm{pg}}$, specific heat of wet grain, $\mathrm{J} / \mathrm{kg}$ dry grain $-{ }^{\circ} \mathrm{C}$

D, coefficient in Wagner's equation, Eq. [11]

E, coefficient in Chung's equation, Eq. [9]

F, coefficient in Chung's equation, Eq. [9]

G, coefficient in Chung's equation, Eq. [9]

$\mathrm{G}_{\mathrm{a}}$, dry air mass velocity, $\mathrm{kg} / \mathrm{s}-\mathrm{m}^{2}$

$\mathrm{G}_{\mathrm{p}}$, dry grain mass velocity, $\mathrm{kg} / \mathrm{s}-\mathrm{m}^{2}$

$\mathrm{h}$, volumetric convective heat transfer coefficient, $\mathrm{J} / \mathrm{m}^{3}-\mathrm{s}-{ }^{\circ} \mathrm{C}$

$\mathrm{h}_{\mathrm{w}}$, enthalpy of liquid water, $\mathrm{J} / \mathrm{kg}$

$\mathrm{H}_{\mathrm{w}}$, enthalpy of water vapor, $\mathrm{J} / \mathrm{kg}$

$\mathfrak{j}$, index designating a compartment in the mesh representing the dryer

$\mathrm{L}$, dryer length, $\mathrm{m}$

$\mathrm{M}$, dry basis moisture content of grain, $\mathrm{kg}$ water $/ \mathrm{kg}$ dry grain

$\mathrm{M}_{\mathrm{a}}$, molecular weight of air, $\mathrm{kg} / \mathrm{kg}$-mole

$\mathrm{M}_{\mathrm{e}}$, equilibrium dry basis moisture content of grain, $\mathrm{kg}$ water $/ \mathrm{kg}$ dry grain

$\mathrm{M}_{\mathrm{w}}$, molecular weight of water, $\mathrm{kg} / \mathrm{kg}$-mole

$\mathrm{n}_{\mathrm{c}}$, index designating a column in the mesh representing the dryer

$\mathrm{n}_{\mathrm{r}}$, index designating a row in the mesh representing the dryer

$\mathrm{N}_{\mathrm{C}}$, number of columns in the mesh representing the dryer

$\mathrm{N}_{\text {IVR }}$, number of the row, just after which the inverter is placed

$\mathrm{N}_{\mathrm{R}}$, number of rows in the mesh representing the dryer

$\mathrm{N}_{\mathrm{RC}}$, number of the row ending the upper section of the dryer, from which no recirculating air is taken

$\mathrm{P}_{\mathrm{c}}$, critical pressure of water, $\mathrm{Pa}$

$P_{v}$, vapor pressure of water, $\mathrm{Pa}$

rh, relative humidity of air, decimal

$\mathrm{rh}_{\mathrm{amb}}$, relative humidity of ambient air, decimal

$\mathrm{r}_{\mathrm{T}^{*} \theta^{*}}(0)$, ratio between rates of change in the dimensionless temperatures of the air and the grain at time zero

$\mathrm{r}_{\mathrm{W}^{*} \mathrm{M}^{*}}(0)$, ratio between the rates of change of the dimensionless air humidity and the grain moisture at time zero

$\mathrm{R}$, drying rate, $\mathrm{kg}$ water $/ \mathrm{kg}$ dry grain $-\mathrm{s}$ 
$\mathrm{R}_{\mathrm{c}}$, characteristic drying rate defined by Eq. [19], $\mathrm{kg}$ water/ $\mathrm{kg}$ dry grain $-\mathrm{s}$

$\mathrm{t}$, time, $\mathrm{s}$

$t_{r}$, residence time of the grain in the dryer, $s$

$\mathrm{T}$, air temperature, ${ }^{\circ} \mathrm{C}$

$\mathrm{T}_{\mathrm{c}}$, critical temperature of water, ${ }^{\circ} \mathrm{C}$

$\mathrm{T}_{\mathrm{r}}$, average temperature of the recirculated air at the outlet of the dryer, ${ }^{\circ} \mathrm{C}$

$\mathrm{U}^{*}$, any dimensionless variable

$\mathrm{V}^{*}$, any dimensionless variable

$\mathrm{W}$, absolute humidity of air in dryer, $\mathrm{kg}$ water/ $\mathrm{kg}$ dry air

$\mathrm{W}_{\mathrm{amb}}$, absolute humidity of ambient air, $\mathrm{kg}$ water $/ \mathrm{kg}$ dry air

$\mathrm{x}$, coordinate along the latitudinal axis of the dryer (see fig. 1), $\mathrm{m}$

$y$, coordinate along the longitudinal axis of the dryer (see fig. 1), $\mathrm{m}$

$y_{r}$, coordinate along the longitudinal axis of the dryer defining the section of the dryer, from which recirculating air is taken, $m$

$\mathrm{z}$, dimensionless parameter in Wagner's equation, Eq. [11]

$\alpha$, dimensionless group defined in Eq. [25a]

$\beta$, dimensionless group defined in Eq. [25b]

$\gamma$, dimensionless group defined in Eq. [25c]

$\delta$, dimensionless group defined in Eq. [25d]

$\epsilon$, bed porosity, $\mathrm{m}^{3}$ pores $/ \mathrm{m}^{3 *}$ total volume

$\theta$, grain temperature, ${ }^{\circ} \mathrm{C}$

$\rho$, density of dry grain, $\mathrm{kg} / \mathrm{m}^{3}$

$\rho_{\mathrm{a}}$, density of dry air, $\mathrm{kg} / \mathrm{m}^{3}$

$\phi$, dimensionless group defined in Eq. [25e]

$\psi$, dimensionless group defined in Eq. [25f]

\section{General Symbols}

$\mathrm{V}_{\text {in }}$, variable $\mathrm{V}$ at the inlet of the dryer

$\mathrm{V}_{\text {out }}$, variable $\mathrm{V}$ at the outlet of the dryer

$V_{o}$, variable $\mathrm{V}$ at the time zero

$\mathrm{V}^{*}$ or $\mathrm{P}^{*}$, dimensionless forms of a variable $\mathrm{V}$ or a parameter $\mathrm{P}$

$\bar{V}$ or $\bar{P}$, average values in space of a variable $V$ or a parameter $P$

$\mathrm{V}$ (s.s) or $\mathrm{V}_{\text {s.s }}$, variable $\mathrm{V}$ at steady-state

$\mathrm{V}_{\mathrm{j}}{ }^{*}$ or $\mathrm{U}_{\mathrm{j}}^{*}$, dimensionless variables $\mathrm{V}^{*}$ or $\mathrm{U}^{*}$ in the $\mathrm{j}^{\text {th }}$ compartment

$<j>$, the grain content of the $\mathrm{j}^{\text {th }}$ compartment 


\section{LITERATURE CITED}

Advanced Continuous Simulation Language (ACSL), Reference Manual.

1986. Concord, Mass.: Mitchell and Gauthier Associates.

American Society of Agricultural Engineers Standards.

1988. Equilibrium moisture content equations and constants. 319.

BAKKER-ARKEMA, F. W., L. E. LEREW, S. F. DEBOER, and M. G. ROTH

1974. Grain Dryer Simulation. Research Report 224. Mich. State Univ.

BAKKER-ARKEMA, F. W., C. FONTANA, and I. P. SCHISLER

1983. Comparison of rice drying systems. Amer. Soc. Agr. Engin. Paper No. 83-3532. St. Joseph, Mich.: ASAE

CHANDRA, P., J. F. THOMPSON, T. R. RUMSEY, and R. P. SINGH

1981. Potential of air recycling in an industrial cross-flow rice dryer. ASAE Paper No. 81-6514. St. Joseph, Mich.: ASAE.

DAVIS, M. E.

1984. Numerical methods and modeling for chemical engineers. p. 128-129. New York, N.Y.: John Wiley \& Sons, Inc.

ELTIGANI, A. Y., and F. W. BAKKER-ARKEMA

1987. Automatic control of commercial cross-flow grain dryers. Drying Technology 5(4):561-75.

FONTANA, C., F. W. BAKKER-ARKEMA, and C. M. WESTELAKEN

1982. Concurrent flow vs. cross-flow drying of long-grain rice. ASAE Paper No. 82-3569. St. Joseph, Mich.: ASAE.

GUI, X. Q., J. BENTSMAN, and J. B. LITCHFIELD

1988. Control of grain drying: State of the art and open problems. ASAE Paper No. 88-3502. St. Joseph, Mich.: ASAE.

HOLTMAN, J. B., and G. L. ZACHARIAH

1969. Computer controls for grain dryers. Trans. Amer. Soc. Agr. Engin. 12(4):433-37.

LAWS, N., and J. L. PARRY

1983. Mathematical modelling of heat and mass transfer in agricultural grain drying. Proc. Roy. Soc. Lond. A 385:169-87.

MARCHANT, J. A.

1985. Control of high temperature continuous flow grain dryers. The Agr. Engin. 40(4):145-49.

OTTEN, L., R. BROWN, and K. ANDERSON

1980. A study of commercial cross-flow grain dryer. Canadian Agr. Engin. 22(2):163-70.

PARRY, J. L.

1985. Mathematical modelling and computer simulation of heat and mass transfer in agricultural grain drying: A review. J. Agr. Engin. Res. 32:1-29.

REID, R. C., J. M. PRAUSNITZ, and B. E. POLING

1987. The properties of gases and liquids. p. 212, 667, 669. New York, N.Y.: McGraw-Hill Book Company.

RUMSEY, T. R.

1986. Transient simulation of a cross-flow rice dryer. Amer. Soc. Agr. Engin. Paper No. 86-6906. St. Joseph, Mich.: ASAE.

1988. State equation model for a cross-flow dryer. Amer. Soc. Agr. Engin. Paper No. 88-6070. St. Joseph, Mich.: ASAE.

SCHISLER, I. P., F. W. BAKKER-ARKEMA, and R. C. BROOK

1982. Control of concurrent flow grain dryers. Amer. Soc. Agr. Engin. Paper No. 82-3613. St. Joseph, Mich.: ASAE.

THOMPSON, T. L., R. M. PEART, and G. H. FOSTER

1968. Mathematical simulation of corn drying-a new model. Trans. Amer. Soc. Agr. Engin. 11(4):582-86.

WANG, C. Y., and R. P. SINGH

1978. A single layer drying equation for rough rice. Amer. Soc. Agr. Engin. Paper No. 78-3001. St. Joseph, Mich.: ASAE.

WANG, C. Y., T. R. RUMSEY, and R. P. SINGH

1979. Convective heat transfer coefficient in a packed bed of rice. Amer. Soc. Agr. Engin. and Canad. Soc. Agr. Engin. Paper No. 79-3040. St. Joseph, Mich.: ASAE.

WHITFIELD, R. D.

1986. An unsteady-state simulation to study the control of concurrent and counter-flow grain dryers. J. Agr. Engin. Res. 33:171-78.

ZACHARIAH, G. L., and G. W. ISAACS

1966. Simulating a moisture-control system for a continous-flow dryer. Trans. Amer. Soc. Agr. Engin. 9:297-302. 

The University of California, in compliance with Tites VI and VII of the Civil Rights Act of 1964, Tide IX of the Education Amendments of 1972, Sections 503 and 504 of the Rehabilitation Act of 1973, and the Age Discrimination Act of 1975, does not discriminate on the basis of race, religion, color, national origin, sex, mental or physical handicap, or age in any of its programs or activities, or with respect to any of its employment policies, practices, or procedures. Nor does the University of Californis or activities, or with respect to any of its employment policies, practices, or procedures. Nor does the University of California of the California Government Code) or because individuals are special disabled veterans or Vietnam en veterans (as defined by the Vietram Era Veterans Readjustment Act of 1974 and Soction 12940 of the California Government Code). Inquiries regarding this policy may be addressed to the Affirmative Action Director, University of California, Agriculture and Natural Resources, 300 Lakeside Drive, 6th Floor, Oakland, CA 94612-3560. (510) $987-0097$. 



\section{HILGARDIA Editorial Board}

Edward S. Sylvester, Chairman, Berkeley (entomology, insecticides, ecology, environmental toxicology)

Peter Berck, Associate Editor, Berkeley (economics, statistics, resource management)

Harry W. Colvin, Associate Editor, Davis (animal science, physiology, breeding, zoology, genetics)

Donald J. Durzan, Associate Editor, Davis (tree fruit and nut crops)

Walter G. Jennings, Associate Editor, Davis (food science, nutrition, and chemistry)

John Letey, Associate Editor, Riverside (soils, plant nutrition, agronomy, agricultural engineering, water)

Irwin P. Ting, Associate Editor, Riverside (botany, plant physiology, biochemistry)

Betsey Tabraham, Acting Editor, Oakland

The Journal HILGARDIA is published irregularly. Number of pages and number of issues vary per annually numbered volume. Address: Agriculture and Natural Resources Publications, University of California, 300 Lakeside Drive, 6th Floor, Oakland, CA 94612-3550. 